Research Article

\title{
Impact of the Adjustment of Maximum Order Volume on Pricing Efficiency of Stock Index Futures in China
}

\author{
Liang Wang $(\mathbb{D}$, Tingjia Xu $(\mathbb{D}$, Longhao Qin $(\mathbb{D}$, and Xianyan Xiong $(\mathbb{D}$ \\ School of Economics and Business Administration, Xi'an University of Technology, Xi'an 710048, China \\ Correspondence should be addressed to Liang Wang; wangliang@xaut.edu.cn
}

Received 26 March 2020; Accepted 21 May 2020; Published 30 June 2020

Academic Editor: Francisco R. Villatoro

Copyright ( $\odot 2020$ Liang Wang et al. This is an open access article distributed under the Creative Commons Attribution License, which permits unrestricted use, distribution, and reproduction in any medium, provided the original work is properly cited.

In April 2017, China Financial Futures Exchange adjusted the maximum order volume of single trading in stock index futures, and this paper conducts research on this event. Firstly, it analyzes the influence of the adjustment of maximum order volume on the characteristics of the limit order book with high-frequency data and the impact of ordering situation on the trading depth and volatility of each contract with panel data. Secondly, it takes high-frequency tick-by-tick data to explore the causal relationship between the ordering situation and the probability of informed trading and analyzes the impact of the event on the probability of informed trading. Finally, the dynamic factor analysis method is used to quantify the pricing efficiency based on the probability of informed trading and the characteristics of limit order book, and the influence of the event on the pricing efficiency of stock index futures market is discussed. The results show that the reduction of maximum order volume has different effects on dominant contracts and nondominant contracts of stock index futures. After the event, the overall trading volume of the market increased, where the trading volume of dominant contracts decreased and that of nondominant contracts increased. For dominant contracts, the depth, slope, and liquidity decrease, the spread increases, and the probability of informed trading decreases so that the pricing efficiency becomes worse, while the results of nondominant contracts are the opposite. For Chinese stock index futures market, the pricing efficiency is greatly reduced and the resource allocation capacity is weakened under the influence of the event. Therefore, the adjustment of maximum order volume is not conducive to the healthy development of the stock index futures market. It is suggested that the reduction of the maximum order volume is only implemented for nondominant contracts.

\section{Introduction}

Information asymmetry is one of the most important issues in the microstructures of financial markets. Starting from the research of Bagehot [1], Glosten et al. [2] proposed that participants in the securities market can be divided into informed traders and uninformed traders. Informed traders are those who have private information related to the real value of assets, while uninformed traders have no private information, or they trade based on public information or rumors. The trading behavior of informed and uninformed traders is a key determinant of market pricing efficiency. When there is information asymmetry in the market, that is, some traders have private information related to the true value of their assets compared to other traders, informed traders may make full use of the information advantage to take a variety of strategic trading behaviors, such as choosing the timing of using private information, splitting orders to hide the information, and deliberately increasing the depth of order book to entice counterparties, which will affect the market pricing efficiency $[3,4]$.

After the stock market crash in Chinese security market in June 2015, the public opinion pointed the problem at stock index futures, believing that speculators used stock index futures to smash the market and caused panic in the market. To solve this issue, China Financial Futures Exchange (CFFEX) increased the trading costs of stock index futures. In August 2015, the trading margins of CSI 300 and SSE 50 stock index futures were all adjusted to more than $30 \%$ of the trading value for the contract, while the standard of market transaction fee for closing today's positions (closing today's newly opened positions) was adjusted to 
$0.015 \%$ of the total transaction amount. In September 2015, the standard of transaction fee was adjusted to $0.23 \%$ of the total transaction amount, while the margin of nonhedging positions was adjusted from $30 \%$ to $40 \%$ of the contract value.

At the beginning of 2017, CFFEX adopted a series of measures including lowering trading costs to improve the liquidity of stock index futures market. On February 17, 2017 , it adjusted the standard of transaction fee to $0.092 \%$ of the total transaction amount; the margin standard for nonhedging positions is modified from $40 \%$ of the contract value to $20 \%$. In April 2017, CFFEX announced that the maximum order volume of limit order and market order of stock index futures would be reduced from 100 to 50 board lots to 20 and 10 board lots, respectively. In September 2017, the standard of transaction fee was adjusted to $0.069 \%$ of the total transaction amount, while the margin was reduced from $20 \%$ of the contract value to $15 \%$.

Therefore, it can be seen that, from June 2015 to the end of 2017, the transaction cost of stock index futures in China experienced a process of first increasing and then decreasing. After the stock market crash in 2015, the margin and transaction fee of stock index futures both increased significantly. In 2017, the trading of stock index futures was gradually extended, the margin and transaction fee began to be lowered, and what is particularly interesting in this process is the downward adjustment of the maximum order volume. $\mathrm{Xu}$ and Liu [5] believed that this reduction only limits the total amount of single orders, which cannot have a substantial impact on the stock index futures market. However, the original intention of lowering the maximum order volume is to reduce the price impact and avoid the instantaneous impact of large orders on the market price, which is conducive to returning the price to the normal level of the market. From the perspective of market microstructure, informed traders can use this rule to split large orders into multiple small orders to better hide their private information, thus affecting the information content in stock index futures prices. At the same time, stock index futures play an important role in Chinese financial market, and the adjustment of maximum order volume will have an impact on the market trading mechanism and liquidity to some extent. Furthermore, it is worth exploring whether this adjustment will affect the composition of market traders and their order quantity and ultimately affect the pricing efficiency of stock index futures market. In addition, the COVID-19 event in 2019 made the financial market more sensitive to information, and stock index future is an important tool for stock market stability in emerging market countries. Therefore, it is of great practical significance to discuss the pricing efficiency of stock index futures from the perspective of microstructure such as the limit order book (LOB). In view of this, this paper explores the relationship between the adjustment of maximum order volume and pricing efficiency of stock index futures from the perspective of the probability of informed trading. It mainly focusing on three issues: (i) the influence of the adjustment of maximum order volume on the characteristics of LOB; (ii) changes in the probability of informed trading caused by the adjustment; and (iii) the influence of the adjustment of maximum order volume on the pricing efficiency of stock index futures based on the probability of informed trading and characteristics of LOB.

As an important financial derivative, the pricing efficiency of stock index futures is the key to improve market liquidity. Different from the market-maker system in Europe, America, and other countries, Chinese stock index futures are automatically matched through an order-driven mechanism. In the order-driven market of continuous auction for stock index futures, the LOB centrally reflects the order submission and matching conditions of the traders at any point in time. The imbalance of orders between buyers and sellers in the order book shows the degree of information asymmetry for financial assets in the market, which also manifests the asymmetric structure between informed and uninformed traders. Informed trading is the key path for private information transmitting to stock prices. Easley et al. [6] believed that the probability of informed trading (PIN) could be used as the direct measurement of informed trading. Then, based on the unbalanced characteristics of orders in the trading order book, Easley et al. [7] proposed an estimation method for the probability of informed trading under high-frequency data from a microperspective, namely, volume-synchronized probability of informed trading (VPIN). In addition, traditional factor analysis, vector autoregression (VAR), and other methods can only consider the static effects of a limited number of variables, which cannot distinguish static and dynamic factors, so that they cannot dynamically, comprehensively, and microscopically reflect the instantaneous effects of multiple factors $[8,9]$. However, the dynamic factor analysis can realize the intertemporal analysis of sample indicators and extract a small number of common factors from the high-dimensional data set and conduct dynamic analysis, so as to make an objective evaluation of the relationship between variables [10]. In view of this, this paper intends to introduce dynamic factor analysis on the basis of VPIN, thereby exploring the impact of the adjustment of maximum order volume on the pricing efficiency of stock index futures in China.

The main contributions of this paper are as follows. First, it constructs the probability of informed trading model and the measurement method of pricing efficiency of Chinese stock index futures. Second, based on the panel data analysis and dynamic factor analysis method, this paper empirically analyzed the influence of the event of "adjustment of the maximum order volume of Chinese stock index futures in April 2017" on the characteristics of LOB, the probability of informed trading, and the pricing efficiency. In addition, the research ideas are as follows. Firstly, it selects the indicators which can reflect the characteristics of LOB to determine the changes in traders' ordering situation caused by the adjustment of maximum order volume, explores the influence of the event on the characteristics of LOB with high-frequency data, and analyzes the influence of order changes on the trading depth and volatility of each contract combined with panel data. Secondly, it measures the probability of informed trading by using high-frequency tick-by-tick data, discusses the causal relationship between the ordering 
situation and the probability of informed trading, and analyzes the influence of the adjustment on the probability of informed trading. Finally, the dynamic factor analysis method is used to quantify the pricing efficiency from the probability of informed trading and the characteristics of $\mathrm{LOB}$, and the influence of the adjustment of maximum order volume on the pricing efficiency of stock index futures market is further analyzed.

\section{Literature Review}

The probability of informed trading refers to the probability that a transaction is made by an informed trader who owns private information or the proportion of an informed trader's transaction in all transactions of an asset. In terms of the probability of informed trading under continuous timesequence transactions, Easley et al. [6] proposed to use the probability of informed trading (PIN) as a direct measure of informed trading and constructed a continuous time sequential trading model (EKOP model) for estimating PIN. In many empirical studies for PIN, Chen et al. [11] took PIN as a measure of private information in stock prices, and the empirical study found that the private information content in stock prices could improve the efficiency of investment decision-making. Brockman and Yan [12] further believe that both inside and outside blockholders can improve the probability of informed trading of stocks. For the measurement of informed trading for irregular interval trading data, Tay et al. [13] applied the asymmetric autoregressive conditional duration (AACD) model of Bauwens and Giot [14] to estimate PIN with irregular interval trading data. Furthermore, the dynamic change in the probability of informed trading between the good news and bad news was distinguished by combining the research framework of Easley et al. [15, 16]. In addition, Chang et al. [17] developed a dynamic intraday measure for the probability of informed trading (DPIN); Weng et al. [18] and Yan and Ouyang [19] verified the effectiveness of DPIN through empirical studies. In recent years, some scholars further explored the measure of the probability of informed trading under the imbalance of order book from the perspective of high-frequency trading. Based on the unbalanced characteristics of orders, Easley et al. [7] proposed volume-synchronized probability of informed trading (VPIN) to estimate PIN. Abad and Yagüe [20], Kitamura and Yoshihiro [21], and Sifat and Mohamad [22] found that VPIN, a new estimation method, is generally regarded as PIN estimation with high-frequency data. Since it does not need maximum likelihood method to estimate unknown parameters, it simplifies the calculation process of the probability of informed trading. Even within a trading day, VPIN can update its value as new information arrives in the market. The related research results of the probability of informed trading are as shown in Table 1.

As for the research on the pricing efficiency of futures, the existing researches are based on the measurement of mispricing rate and study the pricing efficiency from the change in arbitrage space. Some studies have discussed the influence of transaction cost on the pricing efficiency of futures. Fleming et al. [23] explored the reasons for the occurrence of mispricing rate from the perspective of transaction cost, believing that the lower transaction cost makes the pricing efficiency of futures market more efficient. Chakravarty et al. [24] believed that the spread in transaction cost caused by leverage effect and short selling restriction could help to improve the price discovery function and pricing efficiency of futures. Some studies also discussed the pricing efficiency of futures market from the level of price discovery function. Chen and Zheng [3] studied the pricing efficiency, lead-lag relationship, and information efficiency of the SandP 500 index spot and futures markets and put forward that there was a strong correlation between the pricing efficiency of the spot market and the futures market. $\mathrm{Xu}$ and Wan [25] made an empirical analysis of Chinese A-share market and the CSI 300 index futures market and found that the futures market contributed more to the price discovery process. Furthermore, some researches have analyzed the influence of investors' behavior on the pricing efficiency of futures market. Bohl et al. [26] observed that when the share of institutional investors is relatively small, the price discovery function of the futures market is not significant, while as the institutional investors' share increases, the price discovery function and pricing efficiency of the futures market begin to increase. Chen and Chang [27] deduced that the relative trading positions of hedgers negatively affect the pricing efficiency in commodity futures markets, while speculators' positions have positive impacts on pricing efficiency because they correct the pricing errors. Lepone et al. [28] found that the lead-lag relationship of the pricing efficiency between ETF and futures market will not change qualitatively when ETF was used as spot. Liu and Ma [29] studied the impact of arbitrage for Chinese ETF and CSI 300 index futures on pricing efficiency and investor behavior. It is found that, within a certain range, the existence and activity of arbitrage or speculation of stock index futures plays a positive role in modifying market mispricing and improving operation efficiency.

Nowadays, the research on the pricing efficiency of stock index futures market in China mainly discusses the influence of single influencing factor on the pricing efficiency from the perspectives of transaction cost, price discovery, and trader's behavior. Compared with foreign mature markets, Chinese stock index futures trading started relatively late. Scholars pay more attention to the commodity futures market and the interterm arbitrage of futures contracts, and the research on the pricing efficiency has not been fully carried out. According to the microstructure principle of the trading market, if more informed traders exit the stock index futures market, the information content in futures trading will be reduced. The change in the composition of informed and uninformed traders will transform the probability of informed trading and affect the pricing efficiency of the market. At present, there is still a big controversy about the influence mechanism between the probability of informed trading and pricing efficiency in academic circles. Meanwhile, compared with foreign developed markets, Chinese market has significant differences in market regulation and investor structure. In view of this, under the background of frequent regulatory policies on Chinese stock index futures, 
TABLE 1: Related research results of the probability of informed trading.

\begin{tabular}{lcc}
\hline $\begin{array}{l}\text { Research } \\
\text { method }\end{array}$ & Researchers & Application field \\
\hline PIN + EKOP & Easley and O'hara [6]; Chen et al. [11]; Brockman and Yan & [12] \\
PIN + AACD & Petchey et al. [16]; Easley et al. [15]; Tay et al. [13] applied the \\
research of [14] & Continuous time sequential trading \\
DPIN & Chang et al. [17]; Weng et al. [18]; Yan and Ouyang [19] & $\begin{array}{c}\text { Dynamic intraday measurement of the probability of } \\
\text { informed trading }\end{array}$ \\
VPIN & $\begin{array}{c}\text { Easley et al. [7]; Abad and Yagüe [20]; Kitamura and } \\
\text { Yoshihiro [21]; Sifat and Mohamad [22] }\end{array}$ & $\begin{array}{c}\text { The probability of informed trading under the unbalanced } \\
\text { characteristics of order book }\end{array}$ \\
\hline
\end{tabular}

based on the volume-synchronized probability of informed trading (VPIN) by Easley et al. [7], this paper calculates the probability of informed trading through high-frequency data and studies the influence of the adjustment of maximum order volume on the pricing efficiency of stock index futures market in China.

\section{Construction of Pricing Efficiency Model for Stock Index Futures Based on the Probability of Informed Trading and the Characteristics of $\mathrm{LOB}$}

This paper intends to explore the relationship between the adjustment of maximum order volume and the pricing efficiency of stock index futures from the perspective of the probability of informed trading. Firstly, this paper selects the valid indicators based on the characteristics of $\mathrm{LOB}$, which is to determine the impact of the adjustment of maximum order volume on the traders' ordering situation. It analyzes the influence of the adjustment on the characteristics of LOB according to high-frequency data and uses panel data to explore the impact of the ordering situation on the trading depth and volatility of each stock index futures contract. Secondly, this paper measures the probability of informed trading by using high-frequency tick-by-tick data, investigates the causal relationship between the ordering situation and the probability of informed trading, and analyzes the influence of the event on the probability of informed trading. Finally, from the perspective of the probability of informed trading and LOB, it uses dynamic factor analysis to quantify the pricing efficiency, so as to analyze the influence of the adjustment of maximum order volume on the pricing efficiency.

3.1. Characteristics of $L O B$ for Stock Index Futures. Omrane et al. [30] and Siikanen et al. [31] believed that the characteristics of LOB can reflect the market liquidity from a microperspective, and they gave a specific measurement method for the characteristics of LOB from the depth, slope, spread and volatility of the transaction object. Among them, depth is to measure the liquidity of financial product transactions by the total number of pending orders in the bid-ask sequence; spread measures the liquidity of financial products from the perspective of price changes; slope is measured by price elasticity; and volatility uses the weighted average method to calculate the variance.
Therefore, according to the research of Omrane et al. [30], this paper intends to analyze the influence of the adjustment of maximum order volume on the pricing efficiency of stock index futures market from the characteristics of LOB. All the data in this paper are high-frequency tick-bytick data. Since high-frequency data will generate noise, while low-frequency data cannot reflect their characteristics, in this paper, the time-weighted average data of each transaction within a five-minute interval are calculated to reflect the data characteristics within the time interval, as shown below:

$$
\alpha_{t, n}=\frac{\sum_{i=1}^{r_{n}}\left[\left(1 / \tau_{i}\right) \times \alpha_{t, n, i}\right]}{\sum_{i=1}^{r_{n}}\left(1 / \tau_{i}\right)}
$$

where $\alpha$ is the characteristic, $t$ is the day $t, n$ is the $n$-th fiveminute interval, $i$ is the $i$-th data within the five-minute interval, $\tau_{i}$ is the time from the $i$-th data in the $t$-th fiveminute interval to the end of this interval, and $r_{n}$ is the total number of data within the $n$-th five-minute interval. In China, the daily data of stock index futures are mainly divided into two parts: morning and afternoon. The trading time is $9: 30$ to $11: 30$ in the morning and $13: 00$ to $15: 00$ in the afternoon. Since the time interval is five minutes, each trading day is divided into 48 periods.

This paper intends to study the impact of the adjustment of maximum order volume on the pricing efficiency of stock index futures and uses dynamic factor analysis to quantify the pricing efficiency. The selected indicators are the probability of informed trading and four characteristic indicators of LOB, namely, depth, slope, spread, and volatility [30].

3.1.1. Depth (D). Depth measures the trading liquidity of financial products by the total volume of pending orders in the bid-ask sequence. It uses the amount or quantity of financial assets rather than the price. In the futures market, the total amount of orders on the five bid-ask quotes is generally used to represent the depth. The deeper the depth is, the more quotes the trader can choose, the easier the order is to be completed, and the better the liquidity of the product is; otherwise, the product will have poor liquidity. Furthermore, let $l$ represent the tick size; when $l$ is 1 , it represents the optimal quotation; $q$ represents the board lot corresponding $l ; p$ is the corresponding quotation; $a$ is the seller, and $b$ is the buyer. Therefore, depth can be expressed by the following equation: 


$$
D_{n, i}=\sum_{l=1}^{5}\left[q_{n, i, l}^{a} \times p_{n, i, l}^{a}\right]+\sum_{l=1}^{5}\left[q_{n, i, l}^{b} \times p_{n, i, l}^{b}\right] .
$$

The depth characteristic within the $n$-th time interval on day $t$ is

$$
D_{t, n}=\frac{\sum_{i=1}^{r_{n}}\left[\left(1 / \tau_{i}\right) \times D_{t, n, i}\right]}{\sum_{i=1}^{r_{n}}\left(1 / \tau_{i}\right)} .
$$

3.1.2. Spread (QS). Spread measures the liquidity of financial products from the perspective of price changes, that is, the spread between the best (lowest) selling price and the best (highest) buying price in the current market, thus obtaining the potential order execution cost. The larger the spread, the higher the possible cost, and the lower the corresponding liquidity. According to the optimal bid-ask quotes, the bidask spread is

$$
\mathrm{QS}_{n, i}=\left(\frac{p_{n, i, 1}^{a}-p_{n, i, 1}^{b}}{p_{n, i, 1}^{a}+p_{n, i, 1}^{b}}\right)
$$

The spread characteristics within the $n$-th time interval on day $t$ is

$$
\mathrm{QS}_{t, n}=\frac{\sum_{i=1}^{r_{n}}\left[\left(1 / \tau_{i}\right) \times \mathrm{QS}_{t, n, i}\right]}{\sum_{i=1}^{r_{n}}\left(1 / \tau_{i}\right)} .
$$

3.1.3. Slope (SL). Slope denotes the price elasticity of the supply and demand curves, that is, the rate at which the price returns to the original level after large orders enter the market. The higher the amount of capital needed for the price changing in a fixed range, the higher the liquidity of the financial product. The higher the slope, the lower the transaction cost, and the stronger the liquidity of transaction assets; otherwise, the liquidity will be worse. Hence, the buyer's slope of the $i$-th data within the $n$-th time interval can be expressed as $\mathrm{SL}_{n, i}^{a}=(1 / 5)\left[\left(\left(q_{n, i, 1}^{a}\right) /\left(\left(2 p_{n, i, 1}^{a} /\left(p_{n, i, 1}^{a}+\right.\right.\right.\right.\right.$ $\left.\left.\left.\left.\left.p_{n, i, 1}^{b}\right)\right)-1\right)\right)+\sum_{l=1}^{4}\left|\left(\left(q_{n, i, l+1}^{a} / q_{n, i, l}^{a}\right)-1\right) /\left(p_{n, i, l+1}^{a} / p_{n, i, l}^{a}\right)-1\right|\right]$, where the slope of the $i$-th data in the $n$-th time interval is

$$
\mathrm{SL}_{n, i}=\frac{\mathrm{SL}_{n, i}^{a}+\mathrm{SL}_{n, i}^{b}}{2}
$$

The slope characteristic within the $n$-th time interval on day $t$ is

$$
\mathrm{SL}_{t, n}=\frac{\sum_{i=1}^{r_{n}}\left[\left(1 / \tau_{i}\right) \times \mathrm{SL}_{t, n, i}\right]}{\sum_{i=1}^{r_{n}}\left(1 / \tau_{i}\right)} .
$$

3.1.4. Volatility (VO). In order to calculate the volatility of stock index futures, this paper uses the weighted average method to calculate the median price of the $i$-th data in the $n$-th time interval:

$$
M I_{n, i}=\frac{1}{2}\left[\frac{\sum_{l=1}^{5}\left(q_{n, i, l}^{a} \times p_{n, i, l}^{a}\right)}{\sum_{l=1}^{5} q_{n, i, l}^{a}}+\frac{\sum_{l=1}^{5}\left(q_{n, i, l}^{b} \times p_{n, i, l}^{b}\right)}{\sum_{l=1}^{5} q_{n, i, l}^{b}}\right] .
$$

Therefore, the median price characteristic within the $n$ th time interval on day $t$ is

$$
\mathrm{MI}_{t, n}=\frac{\sum_{i=1}^{r_{n}}\left[\left(1 / \tau_{i}\right) \times \mathrm{MI}_{t, n, i}\right]}{\sum_{i=1}^{r_{n}}\left(1 / \tau_{i}\right)} .
$$

Using $\mathrm{MI}_{t, n}$ to calculate logarithmic returns, we can obtain the standard deviation of the rate of return, that is, the volatility, denoted by VO.

3.2. Construction of Measurement Method for the Probability of Informed Trading of Stock Index Futures. The probability of informed trading is the proportion of trading volume from informed traders in all trading volume during the trading period. It is assumed that informed traders are those who have more real information, while the rest are noninformed traders.

According to Easley et al. [32]; within the trading interval $i=l, \ldots, I$, the trader continues to trade, and the trading parameters remain unchanged. If an informed trader finds that his private information makes him profitable when buying, he will buy the underlying asset; if the private information enables him to make a profit when selling, he will sell the underlying asset; if the private information is unable to make himself profitable, he will not trade.

In this section, we use binary tree model to illustrate the occurrence process of informational event (Figure 1), so as to further construct the measurement method for the probability of informed trading for stock index futures. It is assumed that, at the beginning of a trading period, the probability of occurrence for informational event is $\alpha$, while the probability of uninformed event is $1-\alpha$; the event of each trading day is independent. If the probability of good news is $1-\delta$ and the expected closing price is $\overline{s_{i}}$, then the probability of bad news is $\delta$ and its expected closing price is $s_{i}$, where $s_{i}>\overline{s_{i}}$. If no event occurs, the price of underlying asset is $s_{i}^{*}$.

We assume that the trader's buying and selling obey the corresponding independent Poisson process. In any case, for the uninformed trade, the arrival rates of the buyer's order and the seller's order follow the Poisson process with parameters $\varepsilon_{b}$ and $\varepsilon_{s}$, respectively. When there is no informational event, the arrival rate for the informed trader is zero; when bad news or good news occur, his arrival rate follows the Poisson process with parameter $\mu$. In this trading process, $p(t)=\left(p_{n}(t), p_{b}(t), p_{g}(t)\right)$ represents the probability of no news, bad news, and good news, respectively. When $t=0, p(0)=(1-\alpha, \alpha \delta, \alpha(1-\delta))$, then the expected value of the asset is

$$
E\left[s_{i} \mid t\right] p(t)=p_{n}(t) s_{i}^{*}, p_{b}(t) \underline{s_{i}}, p_{g}(t) \overline{s_{i}}, s_{i}^{*}=\delta \underline{s_{i}}+(1-\delta) \overline{s_{i}} .
$$

Furthermore, the probability of selling the informed trader's order at time $t$ is

$$
p_{1}=\frac{\mu p_{b}(t)}{\varepsilon+\mu p_{b}(t)}
$$




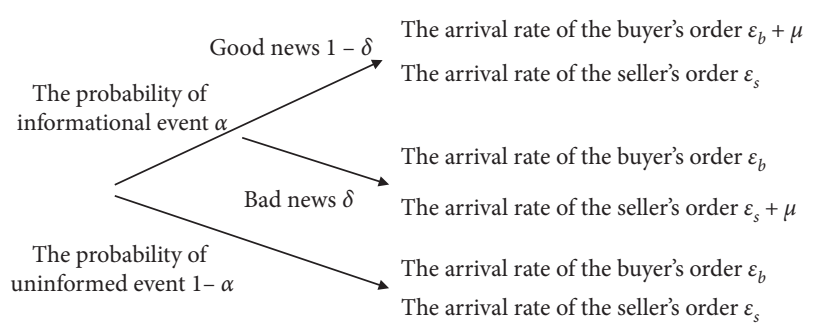

Figure 1: Simulation of a trader placing an order.

The buying price given by the market maker is

$$
B(t)=E\left[s_{i} \mid t\right]-\frac{\mu p_{b}(t)}{\varepsilon+\mu p_{b}(t)}\left(E\left[s_{i} \mid t\right]-\underline{s_{i}}\right) .
$$

And the selling price is

$$
A(t)=E\left[s_{i} \mid t\right]+\frac{\mu p_{g}(t)}{\varepsilon+\mu p_{g}(t)}\left(\overline{s_{i}}-E\left[s_{i} \mid t\right]\right) .
$$

According to Easley, Prado, and O'hara [32], at time $t$, the bid-ask spread is $\sum(t)=A(t)-B(t)$, that is,

$$
\sum(t)=\frac{\mu p_{g}(t)}{\varepsilon+\mu p_{g}(t)}\left(\overline{s_{i}}-E\left[s_{i} \mid t\right]\right)+\frac{\mu p_{b}(t)}{\varepsilon+\mu p_{b}(t)}\left(E\left[s_{i} \mid t\right]-\underline{s_{i}}\right) .
$$

If the probabilities of good news and bad news are equal, the bid-ask spread before the opening is

$$
\sum=\frac{\alpha \mu}{\alpha \mu+2 \varepsilon}\left(\overline{s_{i}}-\underline{s_{i}}\right),
$$

where $\alpha \mu /(\alpha \mu+2 \varepsilon)$ is the probability of informed trading, representing the probability that the initial order is from an informed trader.

However, if we use maximum likelihood method to estimate the probability of informed trading, the accuracy will be affected by parameter estimation. On the contrary, the method cannot update the data in real time and only gets one value per day. Based on the unbalanced characteristics of orders, Easley, Prado, and O'hara [32] proposed a new method for estimating the probability of informed trading, that is, volume-synchronized probability of informed trading $(V P I N)$. It uses high-frequency data to directly calculate the probability of informed trading, avoiding the error in parameter estimation. At the same time, VPIN can constantly update its value according to the arrival of new information in the market.

First of all, this paper selects a certain volume $V$ as separation standard, within any trading day; when the trading volume reaches $V_{\tau}$, let the scale $\tau=1,2, \ldots, n$, where $V_{\tau}$ is a trading basket. Informed trader's buying or selling of the underlying assets based on private information will cause an imbalance of orders in the trading basket, so it is necessary to distinguish between buying and selling orders. In this regard, Easley, Prado, and O'hara [32] proposed bulk volume classification (BVC) that could be used to divide each trading basket into smaller intervals with equal time span, where the volume of buying and selling orders is as follows:

$$
\left\{\begin{array}{l}
V_{\tau}^{B}=\sum_{i=t(\tau-1)+1}^{t(\tau)} V_{i} Z\left(\frac{p_{i}-p_{i-1}}{\sigma_{\Delta p}}\right), \\
V_{\tau}^{S}=\sum_{i=t(\tau-1)+1}^{t(\tau)} V_{i}\left[1-Z\left(\frac{p_{i}-p_{i-1}}{\sigma_{\Delta p}}\right)\right]=V-V_{\tau}^{B},
\end{array}\right.
$$

where $t(\tau)$ is the closing time of the last trade in the $\tau$-th trading basket, $Z$ is the standard normal distribution $\mathrm{cu}^{-}$ mulative function, and $\sigma_{\Delta p}$ is the standard deviation of the price within the interval. It is assumed that $\left|V_{\tau}^{S}-V_{\tau}^{B}\right|$ is the absolute value of the difference between buying and selling orders in the trading basket, so the probability of informed trading is expressed as

$$
V P I N=\frac{\sum_{\tau=1}^{n}\left|V_{\tau}^{S}-V_{\tau}^{B}\right|}{n V} .
$$

If we calculate the probability of informed trading in every 50 trading baskets, then the first probability of informed trading is calculated from the 1st to the 50th trading baskets; the second probability is calculated from the 2nd to the 51st baskets, and so on.

\subsection{Construction of Pricing Efficiency Based on Dynamic} Factors. From the perspective of the probability of informed trading, this paper adopts dynamic factor analysis to quantify the pricing efficiency of stock index futures. The key of factor analysis is to group the indicators according to the correlation so that the indicators are correlated within the group but uncorrelated between groups. Each variable can be described by the sum of the linear function of the common factors and special factors. The common factor in each variable is the fundamental structure formed by the variables within the group, which exists in the expression of each original variable, while the special factor is not included in the common factor. Each special factor and the common factor are independent of each other. For factor analysis, it is mainly used to classify the original variables and explore the correlation; that is, it divides the variables with high correlation into one group and uses the common factors to represent the group. Therefore, this paper constructs a factor model, implements parameter estimation, classifies samples, and obtains the relationship between indicators. Through factor scores, it obtains the importance of different factors, thus making an objective evaluation.

It is assumed that there are $n$ samples and $p$ indicators. Firstly, we use $k$ common factors and a special factor to represent each sample, that is,

$$
X_{i}=a_{i 1} F_{1}+a_{i 2} F_{2}+\cdots a_{i j} F_{j} \cdots+a_{i k} F_{k}+\varepsilon_{i},
$$

where $X_{i}$ represents the observed data of samples, $i=1,2, \ldots, n, j=1,2, \ldots, k ; a_{i j}$ represents the factor 
loading; $F_{j}$ is the common factor; and $\varepsilon_{i}$ is the special factor, and we assume that $\varepsilon_{i} \sim N\left(0, \sigma_{i}^{2}\right)$.

For the first step, we standardize the data of original variables by adopting the $\mathrm{Z}$-score method:

$$
Z_{i j}=\frac{x_{i j}-\overline{x_{j}}}{s_{j}},
$$

where $\overline{x_{j}}=\sum_{i-1}^{n} x_{i j} / n$ and $s_{j}=\sum_{i-1}^{n}\left(x_{i j}-\overline{x_{j}}\right)^{2} / n-1$, and the data sequences that are normalized have a mean of 0 and a variance of 1 . Then, we calculate the matrix $R$ corresponding to the standardized variables:

$$
r_{j k}=\frac{1}{n-1} \sum_{i=1}^{n} \frac{x_{i j}-\overline{x_{j}}}{s_{j}} \frac{x_{i k}-\overline{x_{k}}}{s_{k}},
$$

where $r_{j j}=1$ and $r_{j k}=r_{k j}$.

On this basis, we can get the characteristic root, eigenvector, and contribution rate of the corresponding matrix $R$. The characteristic equation is $\left|\lambda I_{p}-R\right|=0$, where $\lambda_{g}$ is the characteristic root, which represents the proportion of each factor in the evaluation. The vector $L_{g}$ obtained from $\left|\lambda_{g} I_{p}-R\right| L_{g}=0$ is the eigenvector of $\lambda_{g}$, that is, the standardized vector. $a_{g}=\lambda_{g} / \sum_{g=1}^{p} \lambda_{g}$ is the variance contribution rate, indicating the degree of interpretation for the original information.

Next, we determine the number of common factors. If we only analyze the first $k$ factors without considering the later $(p-k)$ factors, then the ratio of the initial observation information is $a(k)=\sum_{g=1}^{k} \lambda_{g} / \sum_{g=1}^{p} \lambda_{g}$. When selecting $k$ and $a(k), k$ should be as low as possible, while $a(k)$ should be as large as possible, so as to obtain more information of the original samples. Normally, $a(k)>85 \%$ is more appropriate.

Then, we calculate the factor load matrix:

$Z=A F$,
where $Z=\left(\begin{array}{c}Z_{1} \\ \vdots \\ Z_{P}\end{array}\right), F=\left(\begin{array}{c}F_{1} \\ \vdots \\ F_{m}\end{array}\right)$, and $A$ is the initial factor load matrix. Through normalizing the eigenvector $U_{i j}$ for the matrix $R$ to get $\Gamma_{i j}=U_{i j} /\left|U_{i j}\right|$ and multiplying $\Gamma_{i j}=U_{i j} /\left|U_{i j}\right|$ and $\sqrt{\lambda},(j=1,2, \ldots, n, m \leq p)$, we can get the initial factor load matrix $A$, that is,

$$
\left(A_{i j}\right)=\left(\Gamma_{i j} \sqrt{\lambda_{i}}\right)
$$

Finally, we use the Thomson method [33] to estimate factor scores:

$$
F_{j}=b_{j 0}+b_{j 1} x_{1}+b_{j 2} x_{2}+\cdots+b_{j p} x_{p} .
$$

Since the variables and factors are normalized, there is $b_{j 0}=0$. According to the least square estimation, the matrix $B=A^{\prime} R^{-1}$ can be obtained, where $R$ is the correlation coefficient matrix of the original variables and $A^{\prime}$ is the transpose of $A$. Furthermore, the estimated value $\widehat{F}_{j}=B Z$ can be deduced from matrix $B$ and matrix $z$. The final variance contribution rate is $w_{j}=\lambda_{j} / \sum_{j=1}^{m} \lambda_{j}$, and the comprehensive evaluating value is $\widehat{F}=\sum_{j=1}^{m} \widehat{F}_{j} w_{j}$.
The above process is a comprehensive evaluation for a single sample. After repeating this process for each sample, we can obtain the corresponding $F$, so as to complete the factor ordering on this basis.

In order to overcome the limitation of factor analysis model in analyzing dynamic time series, this paper adopts a dynamic factor analysis method to study the trading data of stock index futures. This method can conduct the intertemporal analysis of sample indexes and decompose the sample changes into three parts: static structure, average dynamic, and dynamic differences. The basic element $x_{i j t}$ can be represented by the following four parts:

$$
\begin{aligned}
& x_{i j t}=\overline{x_{j}}+\left(\overline{x_{i j}}-\overline{x_{j}}\right)+\left(\overline{x_{j t}}-\overline{x_{j}}\right)+\left(\overline{x_{i j t}}-\overline{x_{j}}-\overline{x_{j t}}+\overline{x_{j}}\right), \\
& \overline{x_{j t}}=\alpha_{j}+\beta_{j t}+\varepsilon_{j t},
\end{aligned}
$$

where $\overline{x_{j}}$ is the mean of a variable, $\overline{x_{i j}}-\overline{x_{j}}$ is the influence of static structure, $\overline{x_{j t}}-\overline{x_{j}}$ is the influence of average dynamic, and $\overline{x_{i j t}}-\overline{x_{j}}-\overline{x_{j t}}+\overline{x_{j}}$ is the influence of dynamic difference in different periods.

In the dynamic factor analysis, the average covariance matrix $S_{T}$ is derived from the covariance matrix $S(t)$ of each period, $S_{T}=1 / T \sum_{t=1}^{T} S(t)$. After extracting the common factors and establishing the original load matrix and the rescaled load matrix, the static score matrix of different samples can be obtained:

$$
c_{i h}=\left(\overline{z_{i}}-\overline{z^{*}}\right)^{\prime} \cdot a_{h},
$$

where $\bar{z}_{i}=1 / T \sum_{t=1}^{T} z_{i t}$ is the average vector of a single sample, $z^{*}=1 / I \sum_{t=1}^{\bar{I}} \frac{z_{i}}{z_{i}}$ is the overall average vector, and $a_{h}$ is the characteristic root vector.

The dynamic score for each sample at time $t$ is

$$
c_{i h t}=\left(z_{i t}-\overline{z_{t}^{*}}\right)^{\prime} \cdot a_{h},
$$

where $\overline{z_{t}^{*}}=1 / I \sum_{t=1}^{I} z_{i t}$ is the average value of each index at time $t$. The average comprehensive score for each sample is the arithmetic mean of its dynamic score.

As mentioned above, the depth, spread, slope, and volatility can well reflect the basic situation of stock index futures, which is of great significance for estimating transaction costs, analyzing differences in market contracts, and selecting appropriate stock index futures contracts for arbitrage, hedging, and speculative transaction. By introducing the characteristics of LOB and the probability of informed trading as the indicators into the factor analysis, we can obtain the following dynamic factor model:

$$
F_{j}=b_{j 0}+b_{j 1} D+b_{j 2} \mathrm{QS}+b_{j 3} \mathrm{SL}+b_{j 4} \mathrm{VO}+b_{j 5} V P I N
$$

where $F_{j}$ is the estimated value of the factor score, $b_{j}$ is the coefficient corresponding to each index, $D$ is the depth, QS is the spread, SL is the slope, VO is the volatility, and VPIN is the probability of informed trading. $D, \mathrm{QS}, \mathrm{SL}$, and VO are the characteristics of LOB. 


\section{Empirical Research}

4.1. Data Selection. Chinese stock index futures market is an order-driven market. The quoted prices are sorted according to the order and time sequence. The exchange automatically matches the transaction based on the sorting situation, and the transaction price is the price of stock index futures contract. When a trader issues an order, it will appear in LOB, which usually has five selling orders and five buying orders, the orders are arranged in order of highest to lowest price; that is, the orders are from Sell 5 to Sell 1 and from Buy 1 to Buy 5. When the price of a trader's selling order is less than or equal to the price of Buy 1, the order will be executed immediately, and the trading volume is the part of the order volume of the selling order that does not exceed the total amount of the buying order within the corresponding price range in the price limit book. When the price of selling order is greater than that of Buy 1, the selling order will appear in LOB. For the buying order, the process and rules of the transaction are similar. Therefore, in the order-driven market, LOB contains the order price and order volume of both buyers and sellers at each moment and records the market behavior. In this paper, LOB comes from the tick-bytick data, and the data are the quoted price and order volume shown in LOB at different times. In addition, the original variables are the order price and volume from Sell 5 to Sell 1 and the order volume, order price, transaction price, and trading volume from Buy 1 to Buy 5.

In Chinese futures market, there are CSI 300 index futures contract (IF), CSI 500 index futures contract (IC), and SSE 50 index futures contract (IH). In order to fully explore the characteristic of stock index futures in China, this paper selects these three kinds of stock index futures contracts as the research object, and the sample period is one month before and after the event occurrence date (April 5, 2017). In the stock index futures market, each traded stock index futures contract can be divided into current-month contract, next-month contract, and quarterly contract. As time goes by, the new contract will replace the old contract, and the next-month contract will become the current-month contract. Hence, no contract can continue trading during the sample period.

The dominant contract is the contract with the largest trading volume in each stock index futures contract. Traders tend to choose the dominant contract with leading price as the main trading object and then formulate reasonable trading strategies on this basis, so as to obtain satisfactory results. In order to ensure the continuity of data, this paper selects the dominant contract as the research object, thus forming a continuous contract.

The trading in stock index futures market is determined by the order of traders, which is not at the same time interval, while the time series data reflecting the trading situation are all at the same interval in econometrics. However, the equalinterval processing of time series will ignore the large amount of information generated in the period with high trading frequency, and make the data unchanged in the period without trading. In order to study the influence of the adjustment of maximum order volume on the pricing efficiency of stock index futures from the perspective of informed traders in market microstructure theory, this paper selects the tick-by-tick data of stock index futures in CSMAR high-frequency database as sample data.

\subsection{The Influence of the Adjustment of Maximum Order} Volume on the Characteristics of LOB. On April 5, 2017, China Financial Futures Exchange (CFFEX) adjusted the maximum order volume of stock index futures trading. The maximum order volume of limit order was reduced to 20 from the previous 100 board lots, and that of market order was decreased from 50 to 10 board lots. After the adjustment, the maximum order volume of each order was only $1 /$ 5 of the previous one. In this section, we quantify the characteristics of LOB before and after the adjustment of maximum order volume. By comparing the traders' ordering situation and the changes in depth, slope, spread, and volatility before and after the event, we analyze the impact of the event on the stock index futures market. Finally, through panel analysis, we compare the impacts of the event on each contract and the relationship between the characteristics of LOB.

The 500-millisecond data in CSMAR high-frequency database come from the interception of the information for LOB twice per second. In this paper, we sort the number of buying and selling orders by time and subtract the amount of pending orders before 0.5 seconds from that after $0.5 \mathrm{sec}-$ onds, so as to obtain the changes in the order within 0.5 seconds. When the number of buying orders decreases, there may be two reasons for it: one is that the selling order is sold, and the other is that the buyer cancels the buying order; when the number of buying orders increases, it means that the buyer increases the pending orders. Similarly, when the selling orders become less, the reason may be that the buying order is sold or the selling order is withdrawn; when the selling orders become more, it means that the seller increases the pending orders. In particular, when the prices of Buy 1 and Sell 1 change, the number of pending orders will also change continuously. Therefore, this section simplifies the above situation by using the changes in the number of orders in each position to represent the instantaneous order volume, that is, the order volume within 0.5 seconds.

Firstly, this section excludes data from the call auction period and selects daily data from $9: 30$ to $11: 30$ and $13: 00$ to $15: 00$ as the research object. By adding the instantaneous order volume of Sell 5 to one Sell 1 and adding that of Buy 1 to Buy 5, it can, respectively, obtain the instantaneous order volume of the selling and buying orders. Furthermore, the instantaneous order volume is summed up in daily units to get the daily order volume.

Figures 2 and 3, respectively, show the changes in the daily order volume of the buying order and selling order for the IC dominant contract within the sample period. Since the trading day is discontinuous, the abscissa in the figures represents the trading data by the ordinal number, while the ordinate represents the daily order volume. The line charts are drawn according to the daily order volume. In addition, the vertical dotted line in Figures 2 and 3 represents the day 


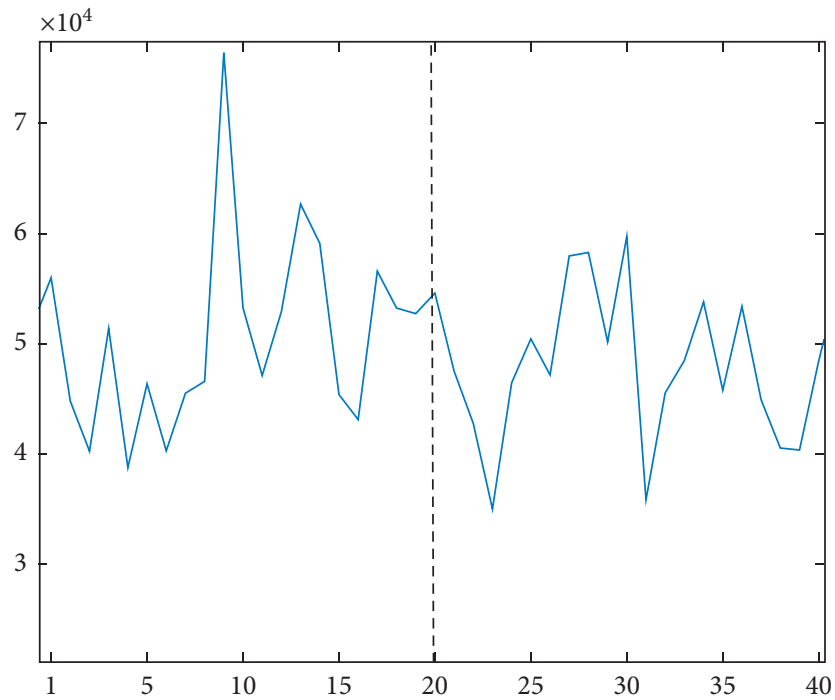

FIgURE 2: The changes in the daily buying order volume for the IC dominant contract.

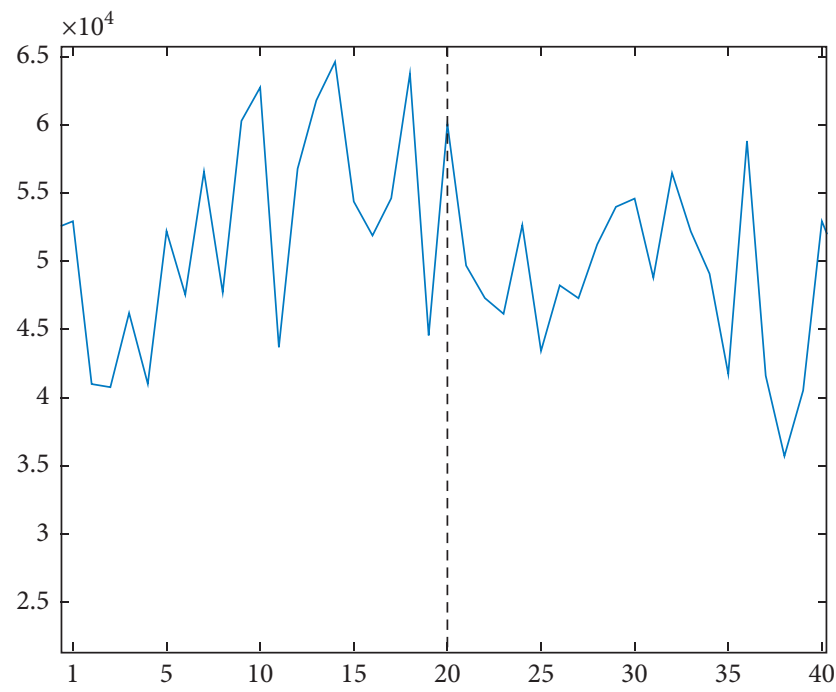

FIgURE 3: The changes in the daily selling order volume for the IC dominant contract.

of the event, the left side of the dotted line describes the change in the order volume on the day before the event, and the right side shows the change in the order volume after the event. It can be seen that the broken line on the right side of the vertical line is obviously below the left broken line in Figure 2, while the right broken line has a significant downward trend compared to the left broken line in Figure 3. Furthermore, in Figure 2, for the buying order of the IC dominant contract, the daily order volume before the event is 50,627 , while it is 47,964 after the event, which is $5.26 \%$ lower than before; in Figure 3, for the selling order of the IC dominant contract, the daily order volume before the event is 52,251 , while it is 49,164 after the event, which is $5.91 \%$ lower than before. From the figures and the change in daily data, it can be shown that the daily order volume the IC dominant contract is significantly reduced by the adjustment of the maximum order volume.

Similar to the calculation of the daily order volume, we sum the order volume of the five-minute interval within the day. By calculating the average value of the order volume per five minutes of the 20 trading days before and after the event, we make the line charts to reflect the intraday changes in the order volume for the IC dominant contract, as shown in Figures 4 and 5. In the figures, the abscissa represents the time sequence. Since the stock index futures market trades for two hours a day, 48 statistical data of order volume can be obtained within a day divided by the time interval of five minutes, and the ordinate represents the order volume.

As can be seen from Figures 4 and 5, the intraday effect of the IC dominant contract is significant. At the beginning and end of the trading, the volume of the buying and selling orders is significantly enlarged, while the order volume is the smallest before and after the midday break. In addition, the change in the order volume before the event is indicated by the solid line, while the change after the event is represented by the dotted line. It can be seen that, in the trading period of one day, the solid line is mostly above the dotted line, indicating the adjustment of the maximum order volume curbs the traders' orders; the angle of the intraday trading proves that the adjustment of the maximum order volume weakens the traders' enthusiasm, thus reducing the volume of both the buying and selling orders. Since the performance of IF and IH dominant contracts is the same as that of IC dominant contract, due to space limitations, the figures and analyses are omitted here.

After the event, the order volume of IC, IF, and IH dominant contracts is significantly reduced, and traders decompose the big order into small orders to make multiple orders so that the conjecture that the trading volume is not affected by the event is inconsistent with the fact. The empirical study shows that the adjustment of the maximum order volume has a negative impact on the trader's order volume, which significantly reduces the trader's orders. Therefore, the information that the relevant departments restrict the trading of stock index futures conveyed the adjustment of the maximum order volume changes the market expectation, thus affecting the traders' strategies.

This paper takes 0.5 seconds as tick data. If the transaction is concluded within $0.5 \mathrm{~s}$, it will be regarded as the completion of an order, and the trading volume represents the order volume. Since ultrahigh frequency (UHF) data will generate noise, while low-frequency data cannot reflect the characteristics of high-frequency data, this paper describes the five-minute interval trading characteristics by calculating the weighted average of the duration of each tick transaction within the five-minute interval. Based on this, the number of orders per five minutes can be further obtained, and then, the daily number of orders for every five minutes will be calculated on a daily basis. The previous analysis has used the data of one month before and after the event to study the main contract. Next, this paper intends to discuss whether the adjustment of maximum order volume has an impact on all the contracts. Since the three stock index futures contracts 


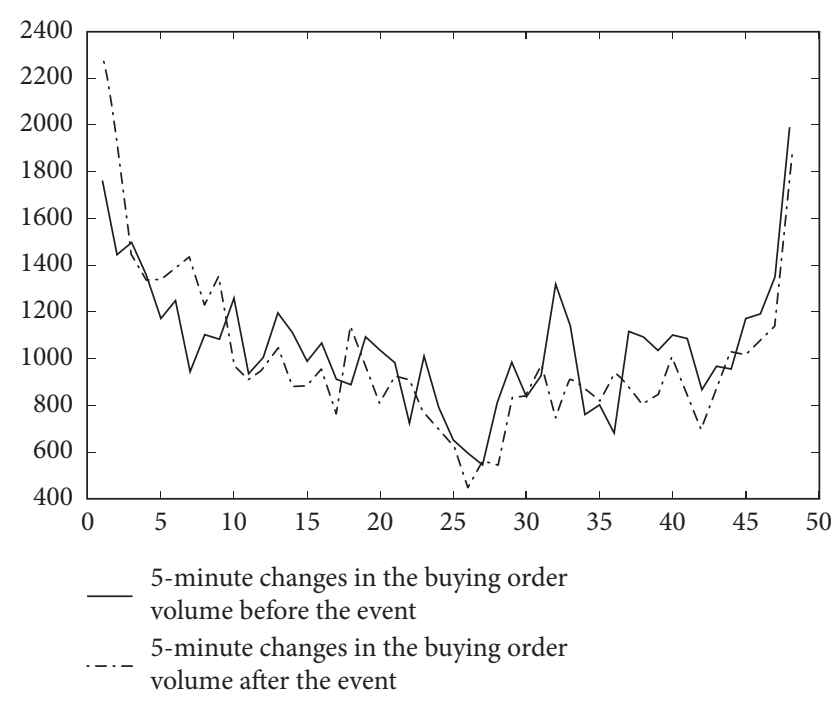

FIgURE 4: The intraday changes in the buying order volume for the IC dominant contract (five minutes).

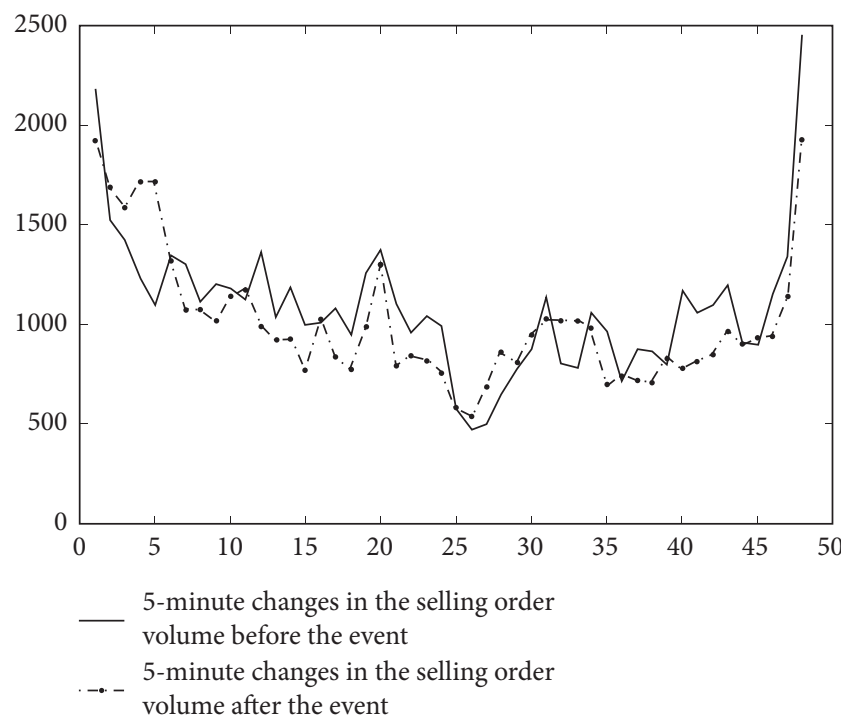

Figure 5: The intraday changes in the selling order volume for the IC dominant contract (five minutes).

have the characteristics of maturity date, limited trading time, and large number of contracts, the consistency of trading time cannot be guaranteed if there are too many research samples. In addition, this paper intends to use the high-frequency data to analyze the short-term impact of the event on the characteristics of LOB, so as to verify the validity of the method, and the sample period should not be too long. Therefore, this paper takes ten trading days before and after the event as the sample period and conducts research on all the sale contracts. The results are shown in Table 2.

As can be seen from Table 2, the number of orders for dominant contracts is much larger than that of other contracts. For IC1704, the dominant contract of CSI 500 stock index futures, the number of orders is significantly reduced after the adjustment of maximum order volume. For the nondominant contracts IC1705, IC1706, and IC1709, they are also trading objects; after the adjustment of maximum order volume, the number of orders is increased to varying degrees, and the transaction becomes active. For the IF and IH contracts, the number of orders for the dominant contract is also reduced, while that of the nondominant contract is increased. Overall, the number of orders for five minutes per day for 12 contracts is 513 before the adjustment of maximum order volume and 593 after the adjustment, where the number of orders for dominant contracts is reduced from 416 to 402 , and the orders for nondominant contracts are enlarged from 97 to 191, indicating that the adjustment of the maximum order volume increases the total number of orders in the stock index futures market, and traders reduce the transactions on dominant contracts, but increase trading on nondominant contracts.

The order volume of the dominant contract is much larger than that of the nondominant contract. It can be seen from Table 1 that, after the adjustment of maximum order volume, the order volume of IC1704 decreases significantly; the order volume of IC1705, IC1706, and IC1709 increases to varying degrees, and the transaction becomes active; for the IF and IH contracts, the number of orders and order volume for the dominant contracts are also reduced, while that of the nondominant contract increases. In general, the order volume of five minutes per day for 12 contracts is 775 before the adjustment of maximum order volume and 864 after the adjustment, where the order volume of dominant contracts is reduced from 661 to 623 and that of nondominant contracts increase from 114 to 241, suggesting that the adjustment of maximum order volume increases the total order volume in the stock index futures market, and traders reduce the transactions on dominant contracts but increase trading on nondominant contracts.

The empirical research shows that the adjustment of maximum order volume has a significant impact on the trading of stock index futures contracts, and it has a completely different influence on the trading of the dominant contract and nondominant contract. The adjustment of maximum order volume promotes the trading of nondominant contracts, restrains the trading of dominant contracts, and increases the total number of orders in the market. Therefore, the event changes the market expectations, which in turn causes traders to change their strategies. Next, we study the changes in the depth, slope, spread for each contract, and the volatility of transaction price to comprehensively analyze the impact of the event on the characteristics of LOB for stock index futures contract.

The depth of the contract reflects the total number of pending orders in the price sequence. It can be seen from Table 2 that, in different stock index futures contracts, the depth of the dominant contract is significantly larger than that of the nondominant contract. The reason is that the dominant contract has the advantage of price guidance, and traders usually focus on it to make strategies. At the same time, due to the large order volume and strong liquidity of 
TABLe 2: Characteristics of LOB for IC, IF, and IH contracts before and after the event.

\begin{tabular}{|c|c|c|c|c|c|c|c|c|c|c|c|c|}
\hline \multirow[b]{2}{*}{ Contract } & \multicolumn{2}{|c|}{$\begin{array}{c}\text { The number of } \\
\text { orders }\end{array}$} & \multicolumn{2}{|c|}{ Order volume } & \multicolumn{2}{|c|}{ Depth } & \multicolumn{2}{|c|}{ Slope } & \multicolumn{2}{|c|}{ Spread } & \multicolumn{2}{|c|}{ Volatility } \\
\hline & $\begin{array}{l}\text { Before } \\
\text { the event }\end{array}$ & $\begin{array}{l}\text { After } \\
\text { the } \\
\text { event }\end{array}$ & $\begin{array}{c}\text { Before } \\
\text { the event }\end{array}$ & $\begin{array}{l}\text { After } \\
\text { the } \\
\text { event }\end{array}$ & $\begin{array}{l}\text { Before } \\
\text { the event }\end{array}$ & $\begin{array}{c}\text { After the } \\
\text { event }\end{array}$ & $\begin{array}{l}\text { Before } \\
\text { the event }\end{array}$ & $\begin{array}{l}\text { After } \\
\text { the } \\
\text { event }\end{array}$ & $\begin{array}{l}\text { Before } \\
\text { the event }\end{array}$ & $\begin{array}{l}\text { After } \\
\text { the } \\
\text { event }\end{array}$ & $\begin{array}{l}\text { Before } \\
\text { the event }\end{array}$ & $\begin{array}{c}\text { After } \\
\text { the } \\
\text { event }\end{array}$ \\
\hline IC1704 & 142 & 135 & 217 & 204 & 120182 & 114784 & 12422 & 10892 & 1.925 & 2.095 & 6.63 & 7.28 \\
\hline IC1705 & 9 & 35 & 10 & 47 & 74836 & 96460 & 2686 & 5269 & 6.65 & 4.621 & 7.38 & 8.60 \\
\hline IC1706 & 11 & 20 & 13 & 24 & 46356 & 88160 & 1955 & 4100 & 2.707 & 5.922 & 4.18 & 8.85 \\
\hline IC1709 & 9 & 8 & 10 & 9 & 77381 & 82361 & 2372 & 2351 & 7.881 & 8.729 & 7.70 & 8.90 \\
\hline IF1704 & 185 & 176 & 313 & 290 & 94594 & 91945 & 11950 & 11330 & 1.376 & 1.442 & 5.48 & 5.58 \\
\hline IF1705 & 10 & 45 & 13 & 61 & 55426 & 58687 & 2541 & 5282 & 5.725 & 3.537 & 7.78 & 7.74 \\
\hline IF1706 & 24 & 25 & 30 & 31 & 51916 & 52458 & 3753 & 4345 & 3.925 & 3.819 & 7.31 & 7.58 \\
\hline IF1709 & 11 & 12 & 12 & 13 & 44335 & 44726 & 2051 & 2490 & 6.123 & 5.576 & 8.31 & 8.12 \\
\hline IH1704 & 89 & 91 & 131 & 129 & 58998 & 51845 & 7156 & 6099 & 2.001 & 2.112 & 6.25 & 6.89 \\
\hline IH1705 & 6 & 28 & 7 & 35 & 35533 & 36925 & 1802 & 3093 & 6.524 & 4.03 & 7.21 & 8.26 \\
\hline IH1706 & 11 & 13 & 13 & 15 & 29228 & 33226 & 2015 & 1926 & 4.851 & 5.115 & 7.38 & 7.99 \\
\hline IH1709 & 6 & 5 & 6 & 6 & 24355 & 29500 & 772 & 1206 & 7.437 & 6.915 & 8.49 & 7.87 \\
\hline
\end{tabular}

the dominant contract, there are a lot of pending orders for traders to choose, which leads to the phenomenon that the depth of the dominant contract is larger. However, the downward adjustment of maximum order volume makes the depth of the nondominant contract become larger but makes the depth of the dominant contract become smaller. This is probably because the reduction of maximum order volume makes the traders have a more negative attitude towards stock index futures trading, so that the pending orders of the dominant contract will decrease, and the liquidity will be weakened; for the nondominant contract, due to its small trading volume, inactive trading, large bid-ask spread, and weak liquidity, large orders may have an instantaneous impact on it, while the adjustment of maximum order volume reduces this impact and improves the transactions of nondominant contract, thus encouraging traders to trade the nondominant contract, increasing the number of pending orders, and increasing its liquidity, which prompts futures to play the role of price leadership.

Slope reflects the resilience of product price after being impacted. The higher the slope, the stronger the resilience of price, and the better the liquidity. As we can see in Table 2, the slope of the dominant contract is significantly higher than that of the nondominant contract, which is consistent with the fact that traders mainly focus on the dominant contract, but the adjustment of maximum order volume makes the slope of the nondominant contract larger but makes the slope of the dominant contract smaller. This shows that, in the nondominant contract transaction, the price elasticity becomes larger. Due to the downward adjustment of maximum order volume, the impact of the maximum order volume on the price becomes smaller, and the speed of price returning to the normal level after being impacted by large orders is accelerated. For the dominant contract, the adjustment of maximum order volume curbs its trading, making the trading activity less affected by the event, and its degree of weakening the slope is greater than the impact of the reduction of large orders. Therefore, the slope of the dominant contract becomes lower, the resilience of price after being impacted by large orders is weakened, and the liquidity is lowered.

Spread reflects the bid-ask spread. The wider the spread, the weaker the liquidity. Table 1 shows that the spread of the dominant contract is significantly smaller than that of the nondominant contract, and this is because the dominant contract has a large number of orders and the participants are numerous so that its bid-ask spread is smaller. In addition, the adjustment of maximum order volume makes the spread of the nondominant contract become smaller, but the spread of the dominant contract becomes larger. Since the downward adjustment of maximum order volume reduces the impact of large orders on the nondominant contract, the transactions of the nondominant contract become more active, the number of orders increases, the bid-ask spread decreases, and the potential transaction costs are reduced. For the dominant contract, the event suppresses the trading, and the information in the quotation is less so that the quotations of buyers and sellers will have greater differences.

Furthermore, it can be seen from Table 1 that the dominant contract has the smallest volatility because the transactions are the most active, and the trading price is relatively stable. After the event, the volatility of the dominant contracts and nondominant contracts increases, indicating that the adjustment of maximum order volume will aggravate the fluctuation of the stock index futures market.

The adjustment of maximum order volume changes the market expectation, which in turn changes the traders' strategies. Since Chinese stock index futures market is the order-driven market, the buying and selling orders determine the price and volume of the contract. In this paper, there are 12 data sets of cross section contracts in the sample period, which belong to panel data with many observations. By using the number of orders to represent the ordering situation, this paper applies the panel data to analyze the impact of the order change caused by the adjustment of order volume on the depth, slope, spread, and volatility of the stock index futures contract, as well as the difference in contracts. The model estimation is as follows: 
TABLE 3: Panel data regression results.

\begin{tabular}{lcccc}
\hline Variable & Coefficient & Std. error & $t$-statistic & Prob. \\
\hline C & 17.14124 & 4.611464 & 3.717093 & 0.0003 \\
D & 0.000437 & $9.34 E-05$ & 8.846659 & 0.0000 \\
QS & -6.958816 & 0.789931 & -8.809398 & 0.0000 \\
VV & 6.439081 & 0.512695 & 12.55929 & 0.0000 \\
SL & 0.004059 & 0.000838 & 4.842295 & 0.0000 \\
\hline
\end{tabular}

Cross section fixed (dummy variables)

$R$-squared

Adjusted $R$-squared

S. E. of regression

Sum squared residuals

Log-likelihood

$F$-statistic

Prob. (F-statistic)

Effects specification

0.940687
0.937551
14.42119
47209.36
-974.3503
300.0123
0.000000

0.940687

14.42119

47209.36

300.0123

$\begin{array}{ll}\text { Mean dependent var } & 46.32500 \\ \text { S. D. dependent var } & 57.70850 \\ \text { Akaike info criterion } & 8.227919 \\ \text { Schwarz criterion } & 8.416454 \\ \text { Hannan-Quinn criter. } & 8.303885 \\ \text { Durbin-Watson stat } & 0.699520\end{array}$

$$
\begin{aligned}
b s_{i t}= & 17.141+\alpha_{i}^{*}+0.000437 d_{i t}+0.004059 s l_{i t} \\
& -6.958816 q s_{i t}+6.44 v v_{i t},
\end{aligned}
$$

where $i$ represents a contract; $t$ represents the trading day; $b s_{i t}$ is the corresponding number of orders; $\alpha_{i}^{*}$ represents the fixed effect; and $d_{i t}, s l_{i t}, q s_{i t}$, and $v v_{i t}$, respectively, represent the depth, slope, spread, and volatility. By using EViews software to analyze the panel data, we get the results in Table 3.

It can be seen from Table 3 that the $P$ values are close to zero, each statistic performs well, and the parameter estimation results are valid. The coefficients of depth and slope are positive, while the coefficient of spread is negative, indicating that the ordering situation is positively correlated with depth and slope and negatively correlated with spread. When the order is reduced, the depth and slope of the market will decrease and the spread will increase, which indicates that the contract liquidity is enhanced.

As can be seen from Table 4, contrary to the fixed effect of the nondominant contract, the order volume of the dominant contract has a positive deviation from the mean value, while that of the nondominant contract has a negative deviation, which is consistent with statistical results. When the maximum order volume is lowered, the order of the dominant contract is reduced, the depth and slope are decreased, the spread is increased, and the liquidity is weakened. For the nondominant contract, the adjustment of maximum order volume reduces the instantaneous impact of large orders on the market, which improves the pricing efficiency, and the market liquidity is improved.

\subsection{The Influence of the Adjustment of Maximum Order} Volume on the Probability of Informed Trading. The probability of informed trading reflects the proportion of informed traders among all traders. In this section, we calculate the probability of informed trading for the dominant contract of the SSE 50 stock index futures (IH) during the sample period and analyze the impact of the adjustment of maximum order volume on the probability of informed trading. Due to space limitations, the results of IC and IF dominant contracts are omitted here.

Figure 6 is a distribution histogram of the probability of informed trading for $\mathrm{IH}$ dominant contract, and Figure 7 is the cumulative distribution function of the probability of informed trading VPIN for IH dominant contract. As can be seen in Figure 6, VPIN does not obey the normal distribution, mostly between 0.12 and 0.18 , and the value greater than 0.5 does not exist. The specific probability can be seen from Figure 7, where the solid line is the empirical distribution function drawn by VPIN. It can be seen that the probability of VPIN being less than 0.15 is 0.6 , the probability of being less than 0.16 is close to 0.9 , and the probability of being greater than 0.16 is only about 0.1 . On the whole, the probability of informed trading is at a normal level, indicating that the overall market operation is stable.

Figure 8 shows the change in the probability of informed trading with time for $\mathrm{IH}$ dominant contract. The abscissa represents the time series, the ordinate represents the probability of informed trading, and the black spot is the time of the adjustment of maximum order volume. It can be seen that, after the event, the probability of informed trading for SSE 50 has a significant decline, which indicates that the adjustment of maximum order volume has a negative impact on the enthusiasm of informed traders to participate in the dominant contract.

In order to explore the relationship between the number of orders $b s$ and the probability of informed trading VPIN, we conduct a Granger causality test. The test results are shown in Tables 5-7.

As can be seen from Table 5, the ADF test of the sequence $b s$ has a statistical value of -7.51638 and $P$ is less than the test level of $1 \%$, so the null hypothesis that $b s$ has a unit root is rejected, and $b s$ is considered to be stable. In Table 6 , the ADF test of the sequence VPIN has a statistical value of -5.794114 and $P$ is below the test level of $1 \%$, so the null hypothesis that VPIN has a unit root that is rejected, and VPIN is considered to be stationary.

In Table 7, there are two null hypotheses of the Granger causality test; the first is " $b s$ is not the Granger cause for VPIN", and the second is "VPIN is not the Granger cause for 
TABLE 4: Fixed effects of IC, IF, and IH contracts.

\begin{tabular}{lcccccccccccc}
\hline Contract & IC1704 & IC1705 & IC1706 & IC1709 & IF1704 & IF1705 & IF1706 & IF1709 & IH1704 & IH1705 & IH1706 & IH1709 \\
Fixed effect & 53 & -16 & -21 & -7 & 97 & -18 & -25 & -23 & 22 & -19 & -25 & -15 \\
\hline
\end{tabular}

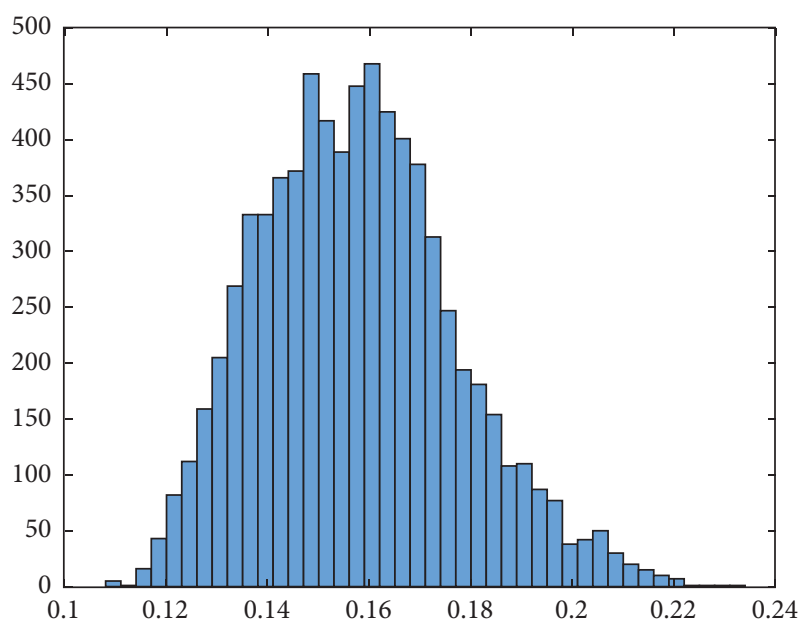

FIGURE 6: IH-VPIN distribution histogram.

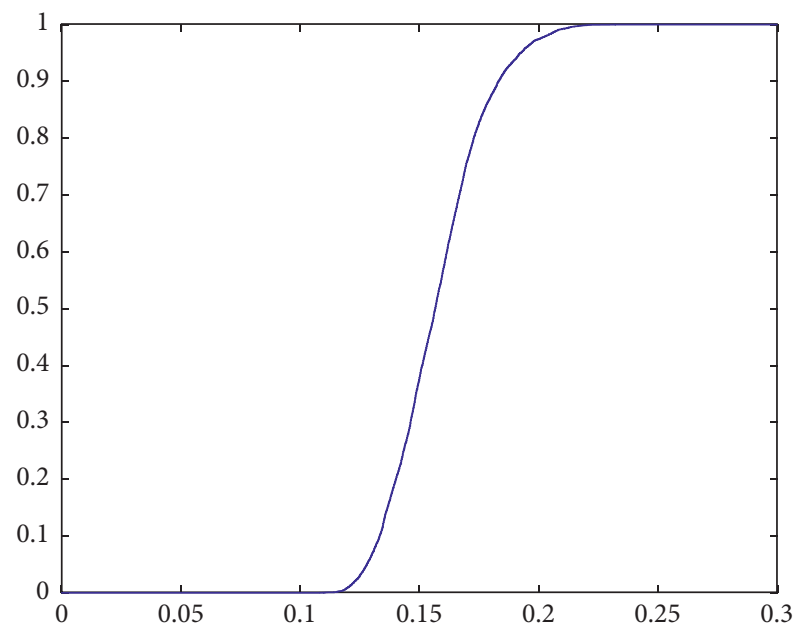

FIGURE 7: IH-VPIN cumulative distribution function.

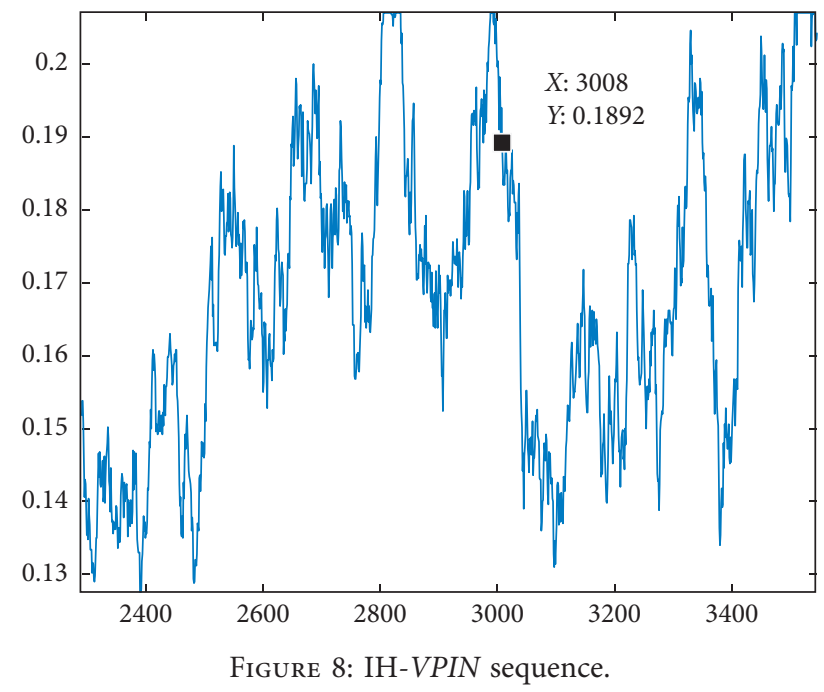

TABLE 5: Unit root test of sequence $b s$ for IH dominant contract.

\begin{tabular}{lcc}
\hline & $t$-statistic & Prob. \\
\hline Augmented Dickey-Fuller test statistic & -7.151638 & 0.0000 \\
Test critical values & & \\
$1 \%$ level & -3.431670 & \\
$5 \%$ level & -2.862008 & \\
$10 \%$ level & -2.567062 & \\
\hline
\end{tabular}

TABLE 6: Unit root test of sequence VPIN for IH dominant contract.

\begin{tabular}{lcc}
\hline & $t$-statistic & Prob. \\
\hline Augmented Dickey-Fuller test statistic & -5.794114 & 0.0000 \\
Test critical values & & \\
$1 \%$ level & -3.431668 & \\
$5 \%$ level & -2.862007 & \\
$10 \%$ level & -2.567062 & \\
\hline
\end{tabular}

TABLE 7: Granger causality test results for IH dominant contract.

\begin{tabular}{lccc}
\hline Null hypothesis & Obs. & F-statistic & Prob. \\
\hline$b s$ is not the Granger cause for VPIN & 4354 & 8.74520 & 0.0002 \\
VPIN is not the Granger cause for $b s$ & & 0.49767 & 0.6080
\end{tabular}

$b s$ ". For the first hypothesis, the F-statistic is 8.74520 , and $P$ is 0.0002 , which is smaller than the test level of $1 \%$. Therefore, the first hypothesis is rejected; that is, $b s$ causes the change in VPIN. For the second hypothesis, the F-statistic is $1.13496, P$ is 0.3299 , which is higher than the test level of $10 \%$, so that the second hypothesis is true, and the change in $b s$ is not caused by VPIN. Hence, according to the above analysis, there is a causal relationship from $b s$ to VPIN, while the reverse causal relationship does not exist (the test results of IF and IC contract are the same as that of IH contract, and the tables are omitted due to space limitation).

The adjustment of maximum order volume will affect the ordering situation of stock index futures contract and further affect the probability of informed trading. This shows that the adjustment of the maximum order volume changes the market expectation, which further changes the trader's strategy and ordering situation, and finally leads to the change in the probability of informed trading.

Furthermore, we analyze the probability of informed trading for other trading contracts before and after the event, and the results are shown in Table 8. It can be deduced that the probabilities of informed trading for the three dominant contracts IC1704, IF1704, and IH1704 are significantly higher than that of the nondominant contracts. This is because the dominant contract is the main trading object for traders, which has a price-driven significance. However, the adjustment of maximum order volume has an opposite effect on both the dominant contract and nondominant contract. After the event, the probability of information trading of 
TABLE 8: The probability of informed trading for IC, IF, and IH contracts.

\begin{tabular}{|c|c|c|c|c|c|c|c|c|c|c|c|c|}
\hline ont & & C1705 & & & & & IF1706 & [F1709 & & 5 & 6 & 09 \\
\hline & & & & & & & & & & & & \\
\hline vent & & & & & & 0.046774 & & & & & & \\
\hline
\end{tabular}

nondominant contracts increases, while that of dominant contracts decreases.

\subsection{Impact of the Adjustment of Maximum Order Volume on the Pricing Efficiency of Stock Index Futures Market. The quotation of informed traders contains a lot of information. In order to explore whether the change in the probability of informed trading will have an impact on the pricing effi- ciency of each contract, this section studies the impact of the adjustment of maximum order volume on the pricing ef- ficiency. This section constructs a comprehensive evaluation index system for the pricing efficiency of the futures market through the factor analysis model, quantifies the pricing efficiency of the market, and displays it in numerical form. The general idea of factor analysis is as follows: firstly, the index system that affects the pricing efficiency of stock index futures market is determined, and then the principal factor analysis is carried out on the final indexes to obtain the secondary index. The principal factor is the influencing factor with an eigenvalue greater than 1 . At the same time, the weight of each principal factor can be derived from the variance contribution rate. Finally, the quantitative index of pricing efficiency can be deduced by multiplying the prin- cipal factor evaluation score obtained by SPSS by the cor- responding weight.}

4.4.1. Impact of the Adjustment of Maximum Order Volume on the Pricing Efficiency of Dominant Contracts. In this section, the dominant contracts of IF, IC, and IH is selected as the sample; the sample period is one month before and after the adjustment of maximum order volume; the probability of informed trading, depth, slope, spread, and volatility are indicators. By using the factor analysis, it quantifies the pricing efficiency of stock index futures. Since the probability of informed trading is the characteristics of each trading basket, we also calculate the depth, slope, spread, and volatility according to the trading basket, keeping the indicators consistent in time. Due to space limitations, we only analyze the results of the IF dominant contract. The data were first standardized using SPSS software, followed by the KMO test and the Bartlett test. As shown in Table 9, the KMO value of the IF dominant contract is close to 0.6 , and the Bartlett test has a $P$ value of 0 , indicating that the selected indicators meet the conditions of factor analysis.

We conduct the principal component analysis on the indicators, as shown in Table 8 . It can be seen that, in the total variance table, the eigenvalues of the first two components for IF contract are all greater than 1 so that we extract these two factors as the principal component factors.
In order to explain their meaning, we rotate the principal component factors by the method of varimax in virtue of SPSS statistical software, and the rotation matrix is deduced as shown in Table 10.

According to Table 11, we select the indicators whose load is greater than 0.5 . In the rotation component matrix of IF dominant contract, the loads of depth and slope on the first principal component factor are higher than 0.9 , and Table 8 shows that the variance contribution rate of the first principal component factor reaches $47 \%$, indicating that depth and slope are important factors affecting the contract pricing efficiency. For the second principal component factor, the volatility, spread, and the probability of informed trading have high loads, all above 0.5 , and its variance contribution rate is $20 \%$ so that the probability of informed trading, volatility, and spread also affect the contract pricing efficiency. Furthermore, we take the proportion of the factor variance in the total variance as the weight of the factor and directly obtain the scores of the principal component factors through using SPSS software. The scores of each factor were weighted and summarized by the corresponding weights of the above calculated factors, and then the pricing efficiency of stock index futures market in the $t$-th trading basket can be deduced, expressed in $F$, which was calculated as follows:

$$
f_{t}=d_{1} f_{1 t}+d_{2} f_{2 t} \text {. }
$$

After obtaining the pricing efficiency of each trading basket from equation (29), we divide the pricing efficiency according to the adjustment of maximum order volume and calculate the mean to deduce the pricing efficiency of IF, IC, and $\mathrm{IH}$ dominant contracts, as shown in Table 12. It can be seen that the adjustment of order volume reduces the pricing efficiency of IF dominant contract. Similarly, Tables 9-12 also show that the analysis results of IC and IH dominant contracts are the same as that of IF dominant contract. Due to space limitations, they will not be explained in detail here.

4.4.2. Impact of the Adjustment of Maximum Order Volume on the Pricing Efficiency of Stock Index Futures Market. In this section, we take ten days before and after the event as the sample period, select all futures contracts: IF1704, IF1705, IF1706, IF1709, IC1704, IC1705, IC1706, IC1709, IH1704, IH1705, IH1706, and IH1709, and use the highfrequency tick-by-tick data as samples. By carrying out dynamic factor analysis, we obtain the daily pricing efficiency and plot the change in pricing efficiency for each contract according to the time sequence.

In Table 13, the two dominant component factors selected in this paper can basically contain the information of five indicators, and only less than $15 \%$ of the information 
TABLE 9: KMO and Bartlett tests.

\begin{tabular}{|c|c|c|c|}
\hline \multicolumn{4}{|c|}{ Contract } \\
\hline IF & $\begin{array}{c}\text { Kaiser-Meyer-Olkin measurement } \\
\text { Bartlett's sphericity test }\end{array}$ & $\begin{array}{c}\text { The approximate chi-square } \\
\text { df } \\
\text { Sig. }\end{array}$ & $\begin{array}{c}0.598 \\
22704.647 \\
10 \\
0.000\end{array}$ \\
\hline IC & $\begin{array}{c}\text { Kaiser-Meyer-Olkin measurement } \\
\text { Bartlett's sphericity test }\end{array}$ & $\begin{array}{c}\text { The approximate chi-square } \\
\text { df } \\
\text { Sig. }\end{array}$ & $\begin{array}{c}0.658 \\
15331.346 \\
10 \\
0.000\end{array}$ \\
\hline $\mathrm{IH}$ & $\begin{array}{c}\text { Kaiser-Meyer-Olkin measurement } \\
\text { Bartlett's sphericity test }\end{array}$ & $\begin{array}{c}\text { The approximate chi-square } \\
\text { df } \\
\text { Sig. }\end{array}$ & $\begin{array}{c}0.721 \\
36622.925 \\
10 \\
0.000\end{array}$ \\
\hline
\end{tabular}

TABle 10: The explanatory total variance.

\begin{tabular}{|c|c|c|c|c|c|c|c|c|c|c|}
\hline \multirow{2}{*}{ Contract } & \multirow{2}{*}{ Component } & \multicolumn{3}{|c|}{ Initial eigenvalue } & \multicolumn{3}{|c|}{ Extract square sum loading } & \multicolumn{3}{|c|}{ Rotation square sum loading } \\
\hline & & Total & $\%$ of variance & Cumulative \% & Total & $\%$ of variance & Cumulative \% & Total & $\%$ of variance & Cumulative \% \\
\hline \multirow{5}{*}{ IF } & 1 & 2.377 & 47.539 & 47.539 & 2.377 & 47.539 & 47.539 & 2.301 & 46.019 & 46.019 \\
\hline & 2 & 1.014 & 20.282 & 67.821 & 1.014 & 20.282 & 67.821 & 1.090 & 21.803 & 67.821 \\
\hline & 3 & 0.948 & 18.962 & 86.783 & & & & & & \\
\hline & 4 & 0.533 & 10.662 & 97.445 & & & & & & \\
\hline & 5 & 0.128 & 2.555 & 100.000 & & & & & & \\
\hline \multirow{5}{*}{ IC } & 1 & 2.515 & 50.302 & 50.302 & 2.515 & 50.302 & 50.302 & 2.344 & 46.884 & 46.884 \\
\hline & 2 & 1.040 & 20.803 & 71.105 & 1.040 & 20.803 & 71.105 & 1.211 & 24.221 & 71.105 \\
\hline & 3 & 0.861 & 17.216 & 88.320 & & & & & & \\
\hline & 4 & 0.469 & 9.386 & 97.707 & & & & & & \\
\hline & 5 & 0.115 & 2.293 & 100.000 & & & & & & \\
\hline \multirow{5}{*}{$\mathrm{IH}$} & 1 & 2.685 & 53.699 & 53.699 & 2.685 & 53.699 & 53.699 & 2.659 & 53.172 & 53.172 \\
\hline & 2 & 0.948 & 18.954 & 72.653 & 0.948 & 18.954 & 72.653 & 0.974 & 19.481 & 72.653 \\
\hline & 3 & 0.894 & 17.884 & 90.537 & & & & & & \\
\hline & 4 & 0.359 & 7.171 & 97.708 & & & & & & \\
\hline & 5 & 0.115 & 2.292 & 100.000 & & & & & & \\
\hline
\end{tabular}

TABle 11: Rotation component matrix.

\begin{tabular}{lcc}
\hline Contract & & Component \\
\hline IF & 1 & 2 \\
Z-score (VPIN) & 0.143 & 0.670 \\
Z-score (dep) & 0.876 & 0.172 \\
Z-score (qsi) & -0.784 & 0.505 \\
Z-score (sli) & 0.948 & 0.086 \\
Z-score (std) & 0.015 & 0.777 \\
\hline IC & & 0.046 \\
Z-score (VPIN) & 0.924 & 0.786 \\
Z-score (dep) & -0.789 & 0.200 \\
Z-score (qsi) & 0.918 & 0.503 \\
Z-score (sli) & 0.153 & 0.105 \\
Z-score (std) & & 0.734 \\
\hline IH & 0.432 & 0.601 \\
Z-score (VPIN) & 0.927 & -0.010 \\
Z-score (dep) & -0.849 & 0.524 \\
Z-score (qsi) & 0.917 & -0.081 \\
Z-score (sli) & -0.221 & 0.890 \\
Z-score (std) & & \\
\hline
\end{tabular}


TABle 12: The pricing efficiency of IF, IC, and IH dominant contracts.

\begin{tabular}{lccc}
\hline & IF & IC & IH \\
\hline Before the event & 0.189173 & 0.186729 & 0.159624 \\
After the event & 0.188856 & 0.183067 & 0.156076 \\
\hline
\end{tabular}

TABle 13: The explanatory total variance.

\begin{tabular}{lccc}
\hline \multirow{2}{*}{ Component } & \multicolumn{3}{c}{ Initial eigenvalues } \\
& Total & \% of variance & Cumulative \% \\
\hline 1 & 3.684 & 73.676 & 73.676 \\
2 & 0.929 & 18.573 & 92.249 \\
\hline
\end{tabular}

may be lost. It can be seen that the contribution rate of variance for the first dominant component factor is $73 \%$ and that of the second dominant component factor is $18 \%$. The cumulative contribution rate is close to $95 \%$, and the eigenvalue is relatively large. Therefore, these two factors are particularly important to the pricing efficiency of each contract.

According to the matrix shown in Table 14, we select the indicators whose load is greater than 0.5 . For the first dominant component factor, the loads of volatility and spread are greater than 0.9 , and Table 13 shows that its variance contribution rate reaches $73 \%$ so that the volatility and spread are important factors affecting the contract pricing efficiency. For the second dominant component factor, slope, depth, and the probability of informed trading have high loads, all above 0.5 , since the variance contribution rate is $18 \%$, it is deduced that the slope, depth, and the probability of informed trading are also crucial factors influencing the contract pricing efficiency.

The score of each contract is calculated and ranked according to the average comprehensive score, as shown in Table 15. It can be seen that the pricing efficiency of IC contracts is above average, while that of other contracts is below average. In order to more intuitively show the change in pricing efficiency of each contract with time, we draw the dynamic factor analysis diagram, as shown in Figure 9.

In Figure 9, the abscissa represents the time sequence of dates, the ordinate represents the pricing efficiency, and the adjustment of maximum order volume occurs in the middle of the abscissa. It can be clearly seen that, for the dominant contracts IC1704, IF1704, and IH1704, their broken lines of start to go down from the middle, indicating that the pricing efficiency of dominant contract is obviously reduced after the event. On the contrary, the nondominant contracts have a significant increase after their broken lines pass through the middle of the abscissa, suggesting that the pricing efficiency of the nondominant contract is improved by the adjustment of maximum order volume.
TABLE 14: Rotation component matrix.

\begin{tabular}{lcc}
\hline & \multicolumn{2}{c}{ Component } \\
& 1 & 2 \\
\hline Z-score (std) & 0.951 & -0.126 \\
Z-score (sli) & -0.786 & 0.575 \\
Z-score (qsi) & 0.947 & -0.094 \\
Z-score (dep) & -0.117 & 0.981 \\
Z-score (VPIN) & -0.769 & 0.520 \\
\hline
\end{tabular}

TABLE 15: Scores of IC, IF, and IH contracts.

\begin{tabular}{lccc}
\hline Contract & Average composite score & Static factor score & Rank \\
\hline IC1709 & 0.516 & 0.634 & 1 \\
IC1706 & 0.395 & 0.472 & 2 \\
IC1704 & 0.199 & 0.394 & 3 \\
IC1705 & 0.095 & 0.201 & 4 \\
IF1704 & -0.027 & -0.046 & 5 \\
IH1709 & -0.038 & -0.075 & 6 \\
IF1709 & -0.069 & -0.103 & 7 \\
IH1706 & -0.097 & -0.124 & 8 \\
IH1704 & -0.170 & -0.192 & 9 \\
IF1706 & -0.173 & -0.196 & 10 \\
IF1705 & -0.296 & -0.325 & 11 \\
IH1705 & -0.330 & -0.402 & 12 \\
\hline
\end{tabular}

Furthermore, we take the trading volume of each contract as the weight to derive the overall pricing efficiency of the stock index futures market, which is 0.527 before the adjustment of maximum order volume and -0.438 after the adjustment. It indicates that the overall pricing efficiency of the stock index futures market declined significantly after the adjustment of maximum order volume. In order to analyze the causes of this phenomenon, we compare the contract pricing efficiency before and after the adjustment, as shown in Table 16. In Table 16, the data are the arithmetical average of the sample period before and after the event, and it can be seen that, before the adjustment of maximum order volume, the pricing efficiency of dominant contracts is better than that of the nondominant contracts; after the event, the pricing efficiency of dominant contracts decrease significantly, while that of the nondominant contracts are improved. Due to the small proportion of nondominant contract trading in the overall stock index futures market, if the same weight is given to each contract, the results will not be objective. Therefore, this paper takes the trading volume as the weight for study, and the results show that the adjustment of maximum order volume weakens the overall pricing efficiency of the stock index futures market. The stock index futures contract has guiding significance for price. Since the pricing efficiency of stock index futures market is the performance of trading market data and the grasp of the actual situation of the overall operation, its reduction means the decrease in the operation efficiency for financial market, resource allocation capacity, and price discovery function. 


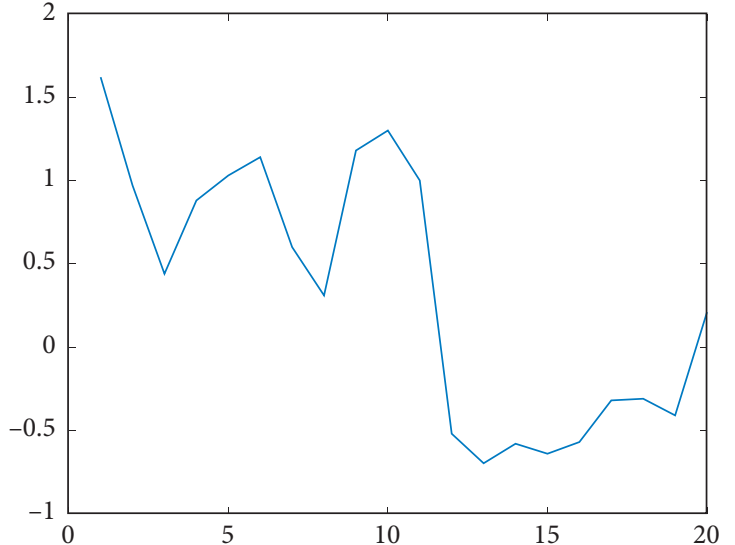

(a)

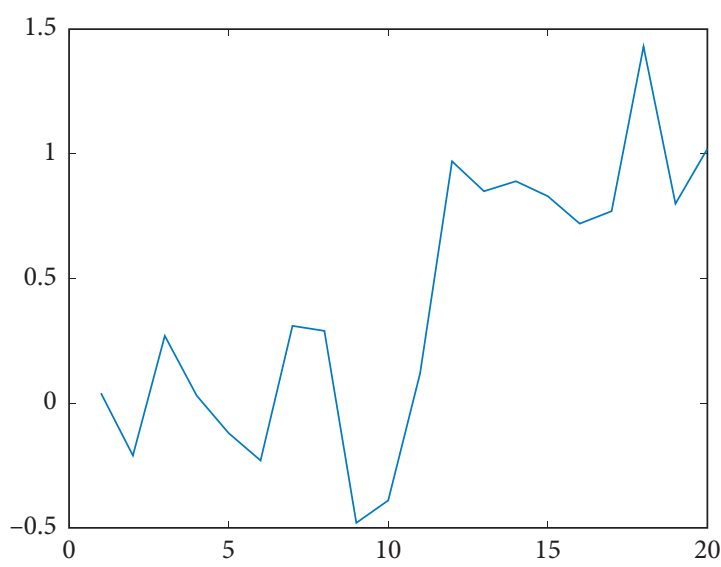

(c)

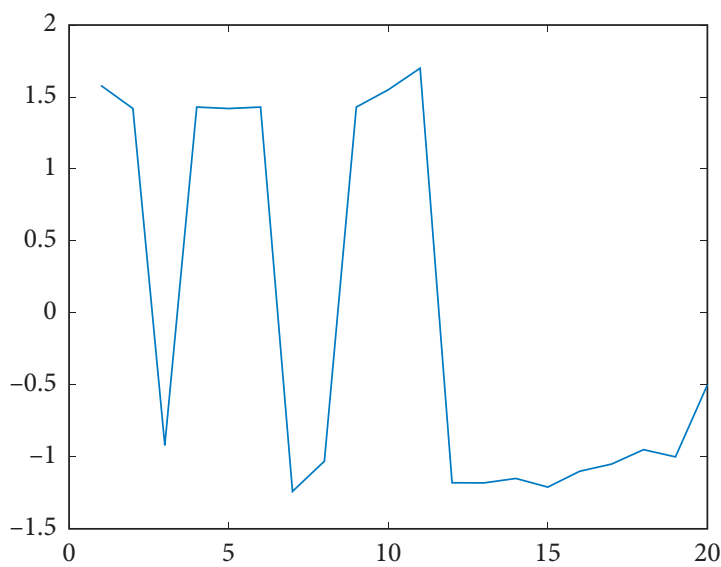

(e)

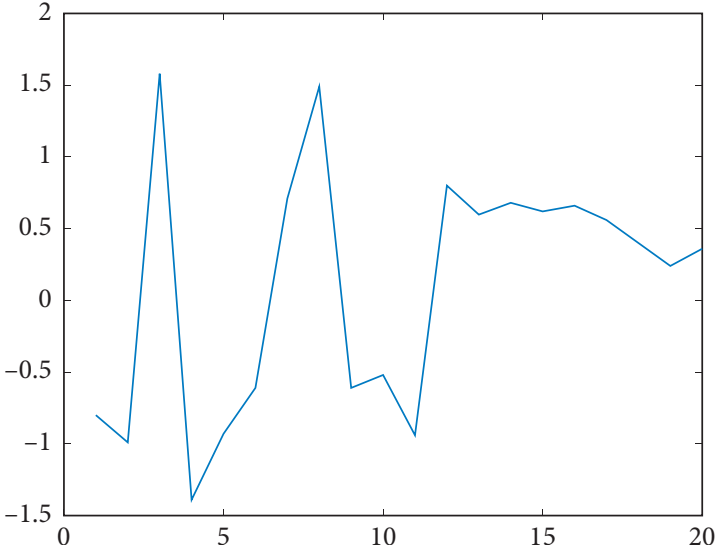

(b)

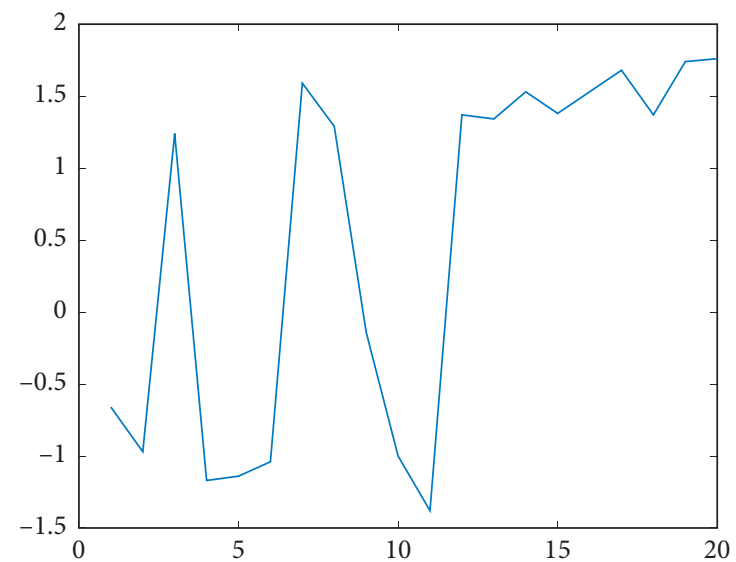

(d)

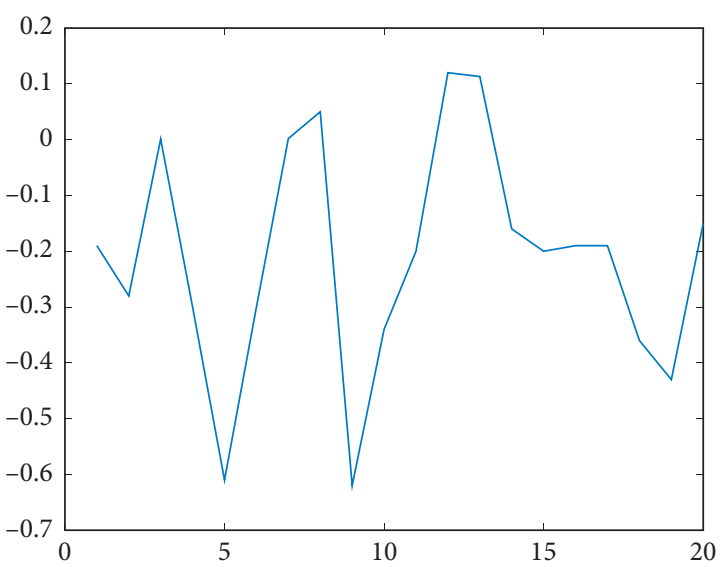

(f)

Figure 9: Continued. 


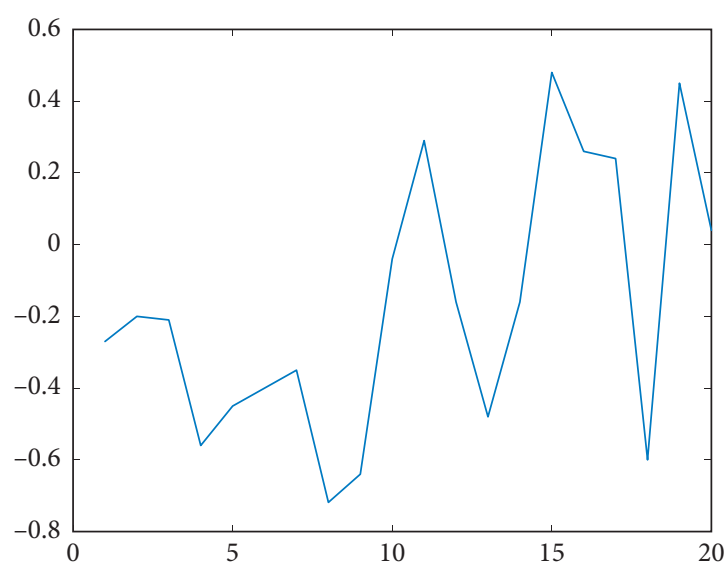

(g)

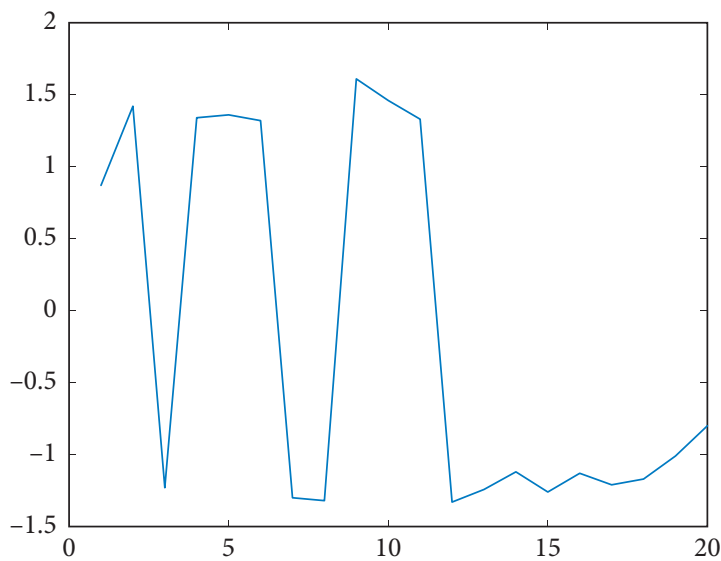

(i)

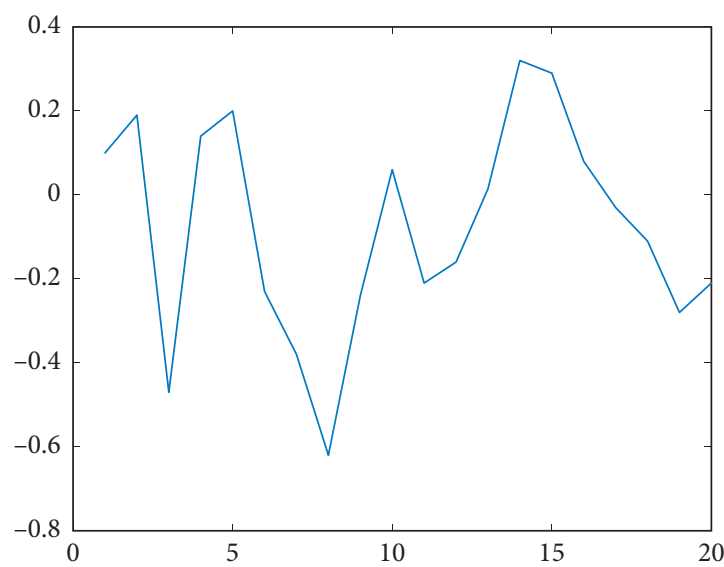

(k)

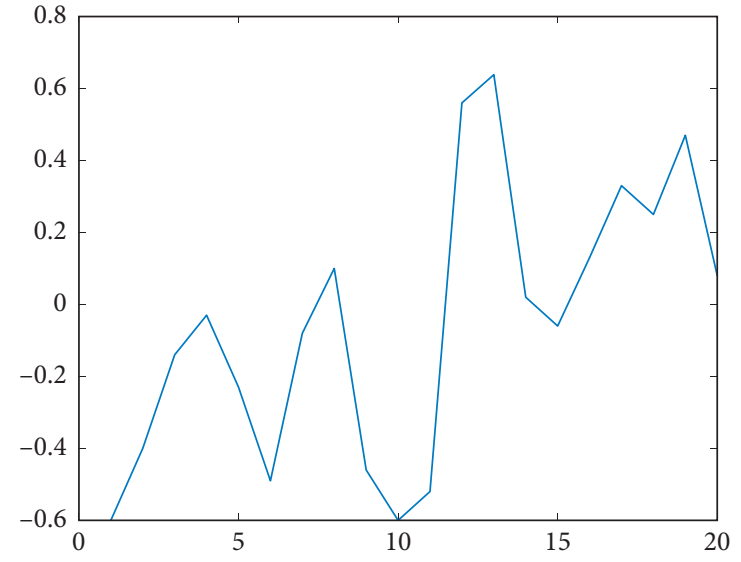

(h)

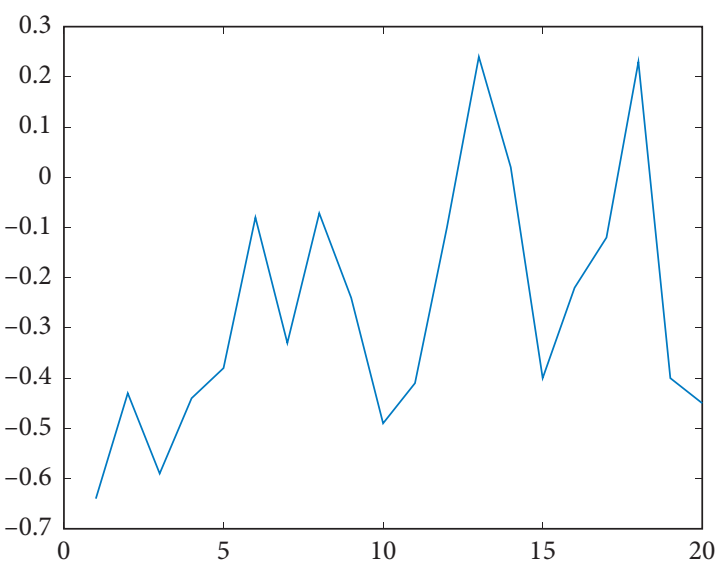

(j)

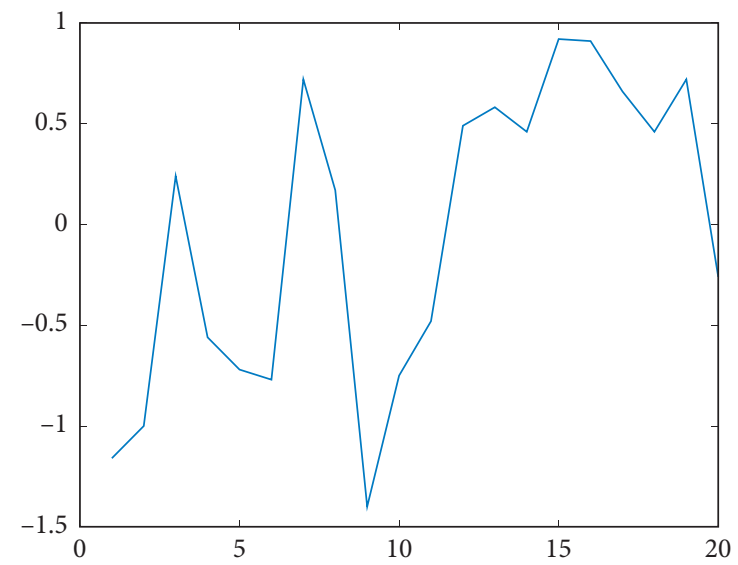

(l)

FIgUre 9: Dynamic factor analysis of pricing efficiency for IC, IF, and IH contracts: (a) IC1704; (b) IC1705; (c) IC1706; (d) IC1709; (e) IF1704; (f) IF1705; (g) IF1706; (h) IF1709; (i) IH1704; (j) IH1705; (k) IH1706; (l) IH1709. 
TABLE 16: The pricing efficiency of IC, IF, and IH contracts.

\begin{tabular}{lcc}
\hline Contract & Before the event & After the event \\
\hline IC1704 & 0.65 & -0.25 \\
IC1705 & -0.20 & 0.39 \\
IC1706 & -0.04 & 0.83 \\
IC1709 & -0.20 & 1.23 \\
IF1704 & 0.70 & -0.76 \\
IF1705 & -0.22 & -0.37 \\
IF1706 & 0.03 & -0.38 \\
IF1709 & -0.32 & 0.18 \\
IH1704 & 0.55 & -0.89 \\
IH1705 & -0.29 & -0.36 \\
IH1706 & -0.12 & -0.06 \\
IH1709 & -0.52 & 0.44 \\
The overall market & 0.527 & -0.438 \\
\hline
\end{tabular}

\section{Conclusion}

In April 2017, China Financial Futures Exchange adjusted the maximum order volume of stock index futures. This paper conducts research to explore the impact of this event on the pricing efficiency of Chinese stock index futures market and various contracts. Firstly, this paper selects indicators that can reflect the characteristics of LOB to study the changes in traders' order conditions caused by the adjustment of maximum order volume. It analyzes the influence of the event on the characteristics of LOB with high-frequency data and the influence of order conditions on the trading depth of each contract with panel data. Secondly, it uses high-frequency tick-by-tick data to measure the probability of informed trading, explores the causal relationship between the ordering situation and it, and analyzes the impact of the event on it. Finally, this paper divides the indicators of liquidity and volatility according to the trading basket, quantifies the pricing efficiency of futures contracts through dynamic factor analysis based on the probability of informed trading and the characteristics of LOB, and determines the pricing efficiency of overall stock index futures market according to the weight of each contract, so as to deduce the influence of the adjustment of maximum order volume on the pricing efficiency. We have the following conclusions:

(i) The impacts of the adjustment of maximum order volume on the characteristics of LOB are as follows: (i) the adjustment of maximum order volume changes the traders' strategies, and the traders' orders have opposite adjustment in dominant contracts and nondominant contracts of stock index futures. After the reduction of maximum order volume, the overall market trading volume increases, where the traders' enthusiasm for dominant contracts decreases, and the trading volume of nondominant contracts increases. (ii) Affected by the change in orders, for dominant contracts, the depth and slope decrease, the spread increases, and the liquidity is reduced; for nondominant contracts, the depth and slope increase, the spread decreases, and the liquidity is improved. (ii) The adjustment of maximum order volume weakens the probability of informed trading for dominant contracts, and the proportion of informed traders in dominant contracts decreases; the probability of informed trading for nondominant contracts is improved, and informed traders prefer nondominant contracts after the event.

(iii) Influenced by the reduction of maximum order volume, the pricing efficiency of dominant contracts is lowered, while that of nondominant contracts are improved. However, as for the overall stock index futures market, since dominant contracts account for the majority of the total transactions, the pricing efficiency of the stock index futures market is greatly reduced and the resource allocation capacity is weakened under the influence of the event. The adjustment of maximum order volume is not conducive to the healthy development of the stock index futures market.

This paper has the following deficiencies: first, due to space limitations, this paper only studies the impact of the adjustment of the maximum order volume on the pricing efficiency of Chinese stock index futures from the perspective of microstructure, without considering macrofactors such as stock market trends and the impact of international financial markets for comprehensive analysis. Second, this study only takes high-frequency data for analysis, without combining the behavioral and psychological heterogeneity of traders and using daily trading data (low-frequency data). Therefore, the research conclusions need to be further deepened. In addition, further research can be conducted from the perspective of behavioral finance in the future by combining macroeconomic conditions and traders' behavioral and psychological heterogeneity.

\section{Data Availability}

The authors declare that the data will be available upon acceptance of this article. The data used to support the findings of this study are included within the article; it is true and reliable. Further data are available from the corresponding author upon request.

\section{Conflicts of Interest}

The authors declare that there are no conflicts of interest regarding the publication of this paper.

\section{Acknowledgments}

This work was supported by the National Natural Science Foundation of China (Grant number 71171155), Xi'an Social Sciences Planning Fund Major Projects (Grant number 17J92), Special Scientific Research Project of Education Department of Shaanxi Province (Grant numbers 18JK0535 and 16JK1527), Xi'an Development and Reform Commission Regional Economic Issues (Grant number SXTY2018-08-15), Humanities and Social Sciences Research Planning Fund of 
Ministry of Education (Grant number 19YJA630080), and 2020 Natural Science Basic Research Project of Shaanxi Province (Grant number 2020JM-447).

\section{References}

[1] W. Bagehot, "The only game in town," Financial Analysts Journal, vol. 27, no. 2, pp. 12-14, 1971.

[2] L. R. Glosten, P. R. Milgrom, and R. Lawrence, "Bid, ask and transaction prices in a specialist market with heterogeneously informed traders," Journal of Financial Economics, vol. 14, no. 1, pp. 71-100, 1985.

[3] R. Chen and Z.-1. Zheng, "Unbiased estimation, price discovery, and market efficiency: futures prices and spot prices," Systems Engineering-Theory \& Practice, vol. 28, no. 8, pp. 2-11, 2008.

[4] Y. S. Alhaj-Yaseen, J. T. Barkoulas, and A. Ouandlous, "Liberalization and asymmetric information flow dynamics in the Chinese equity markets," The Journal of Economic Asymmetries, vol. 21, Article ID e00151, 2020.

[5] R. Xu and C. Liu, "Research on the impact of restricted trading of stock index futures on pricing efficiency-an empirical study based on cross-market information transmission," Economic Theory and Business Management, vol. 37, no. 1, pp. 61-74, 2018.

[6] D. Easley and M. O'hara, "Price, trade size, and information in securities markets," Journal of Financial Economics, vol. 19, no. 1, pp. 69-90, 1987.

[7] D. Easley, M. M. López de Prado, and M. O’Hara, “The microstructure of the "flash crash:" flow toxicity, liquidity crashes, and the probability of informed trading," The Journal of Portfolio Management, vol. 37, no. 2, pp. 118128, 2011.

[8] C. Aßmann, J. Boysen-Hogrefe, and M. Pape, "Bayesian analysis of static and dynamic factor models: an ex-post approach towards the rotation problem," Journal of Econometrics, vol. 192, no. 1, pp. 190-206, 2016.

[9] C. H. Chu, M. N. Lo Huang, S. H. Huang et al., "Bayesian structure selection for vector autoregression model," Journal of Forecasting, vol. 38, no. 3, pp. 1-29, 2019.

[10] M. Barigozzi and M. Hallin, "Generalized dynamic factor models and volatilities: consistency, rates, and prediction intervals," Journal of Econometrics, vol. 216, no. 1, pp. 4-34, 2020.

[11] Q. Chen, I. Goldstein, and W. Jiang, "Price informativeness and investment sensitivity to stock price," Review of Financial Studies, vol. 20, no. 3, pp. 619-650, 2007.

[12] P. Brockman and X. Yan, "Block ownership and firm-specific information," Journal of Banking \& Finance, vol. 33, no. 2, pp. 308-316, 2009.

[13] A. Tay, C. Ting, Y. K. Tse, and M. Warachka, "Using highfrequency transaction data to estimate the probability of informed trading," Journal of Financial Econometrics, vol. 7, no. 3, pp. 288-311, 2009.

[14] L. Bauwens and P. Giot, "Asymmetric ACD models: introducing price information in ACD models," Empirical Economics, vol. 28, no. 4, pp. 709-731, 2003.

[15] D. Easley, S. Hvidkjaer, and M. O'Hara, "Is information risk a determinant of asset returns?" The Journal of Finance, vol. 57, no. 5, pp. 2185-2221, 2002.

[16] J. Petchey, M. Wee, and J. Yang, "Pinning down an effective measure for probability of informed trading," Pacific-Basin Finance Journal, vol. 40, no. part_PB, pp. 456-475, 2016.
[17] S. S. Chang, L. V. Chang, and F. A. Wang, "A dynamic intraday measure of the probability of informed trading and firm-specific return variation," Journal of Empirical Finance, vol. 29, pp. 80-94, 2014.

[18] P.-S. Weng, M.-H. Wu, M.-L. Chen, and W.-C. Tsai, "An empirical analysis of the dynamic probability of informed institutional trading: evidence from the Taiwan futures exchange," Journal of Futures Markets, vol. 37, no. 9, pp. 865-891, 2016.

[19] Y. Tsai and H. Ouyang, "Dynamic probability of informed trading and price movements: evidence from the CSI300 index futures market," Applied Economics Letters, vol. 25, no. 13-15, pp. 998-1003, 2018.

[20] D. Abad and J. Yagüe, "From PIN to VPIN: an introduction to order flow toxicity," The Spanish Review of Financial Economics, vol. 10, no. 2, pp. 74-83, 2012.

[21] Y. Kitamura, "The probability of informed trading measured with price impact, price reversal, and volatility," Journal of International Financial Markets, Institutions and Money, vol. 42, pp. 77-90, 2016.

[22] I. M. Sifat and A. Mohamad, "Circuit breakers as market stability levers: a survey of research, praxis, and challenges," International Journal of Finance \& Economics, vol. 24, no. 3, pp. 1130-1169, 2019.

[23] J. Fleming, B. Ostdiek, and R. E. Whaley, "Trading costs and the relative rates of price discovery in stock, futures, and option markets," Journal of Futures Markets, vol. 16, no. 4, pp. 353-387, 1996.

[24] S. Chakravarty, H. Gulen, and S. Mayhew, "Informed trading in stock and option markets," The Journal of Finance, vol. 59, no. 3, pp. 1235-1257, 2004.

[25] F. Xu and D. Wan, "The impacts of institutional and individual investors on the price discovery in stock index futures market: evidence from China," Finance Research Letters, vol. 15, pp. 221-231, 2015.

[26] M. T. Bohl, C. A. Salm, and M. Schuppli, "Price discovery and investor structure in stock index futures," Journal of Futures Markets, vol. 31, no. 3, pp. 282-306, 2011.

[27] Y.-L. Chen and Y.-K. Chang, "Investor structure and the informational efficiency of commodity futures prices," International Review of Financial Analysis, vol. 42, pp. 358-367, 2015.

[28] A. Lepone, J. Wen, and J. Y. Yang, "Message traffic restrictions and relative pricing efficiency: evidence from index futures contracts and exchange-traded funds," Pacific-Basin Finance Journal, vol. 51, pp. 366-375, 2018.

[29] L. Liu and C. Ma, "Research on the arbitrage and pricing efficiency of China stock index futures market," Journal of Management Sciences in China, vol. 16, no. 3, pp. 41-52, 2013.

[30] W. B. Omrane, Y. Tao, and R. Welch, "Scheduled macro-news effects on a Euro/US dollar limit order book around the 2008 financial crisis," Research in International Business \& Finance, vol. 42, pp. 9-30, 2017.

[31] M. Siikanen, J. Kanniainen, and J. Valli, "Limit order books and liquidity around scheduled and non-scheduled announcements: empirical evidence from NASDAQ Nordic," Finance Research Letters, vol. 21, pp. 264-271, 2017.

[32] D. Easley, M. M. López de Prado, and M. O'Hara, "Flow toxicity and liquidity in a high-frequency world," Review of Financial Studies, vol. 25, no. 5, pp. 1457-1493, 2012.

[33] G. H. Thomson and W. Ledermann, "The Influence of multivariate selection on the factorial analysis of ability," British Journal of Psychology, vol. 29, no. 3, pp. 288-306, 1939. 